\title{
Connexin Signaling Is Involved in the Reactivation of a Latent Stem Cell Niche after Spinal Cord Injury
}

\author{
Gabriela Fabbiani, ${ }^{\star}$ Cecilia Reali, ${ }^{\star}$ Adrián Valentín-Kahan, ${ }^{\star}$ María Inés Rehermann, Jimena Fagetti, María Victoria Falco, \\ and ${ }^{\circ}$ Raúl E. Russo \\ Neurofisiología Celular y Molecular, Instituto de Investigaciones Biológicas Clemente Estable, CP 11600, Montevideo, Uruguay
}

\begin{abstract}
The ependyma of the adult spinal cord is a latent stem cell niche that is reactivated by spinal cord injury contributing new cells to the glial scar. The cellular events taking place in the early stages of the reaction of the ependyma to injury remain little understood. Ependymal cells are functionally heterogeneous with a mitotically active subpopulation lining the lateral domains of the central canal (CC) that are coupled via gap junctions. Gap junctions and connexin hemichannels are key regulators of the biology of neural progenitors during development and in adult neurogenic niches. Thus, we hypothesized that communication via connexins in the CC is developmentally regulated and may play a part in the reactivation of this latent stem cell niche after injury. To test these possibilities, we combined patch-clamp recordings of ependymal cells with immunohistochemistry for various connexins in the neonatal and the adult $(\mathrm{P}>90)$ normal and injured spinal cord of male and female mice. We find that coupling among ependymal cells is downregulated as postnatal development proceeds but increases after injury, resembling the immature CC. The increase in gap junction coupling in the adult $\mathrm{CC}$ was paralleled by upregulation of connexin 26 , which correlated with the resumption of proliferation and a reduction of connexin hemichannel activity. Connexin blockade reduced the injury-induced proliferation of ependymal cells. Our findings suggest that connexins are involved in the early reaction of ependymal cells to injury, representing a potential target to improve the contribution of the CC stem cell niche to repair.
\end{abstract}

Key words: connexin 26; connexin 43; endogenous progenitors; gap junctions and connexin hemichannels; latent stem cell niche; spinal cord injury

\section{Significance Statement}

Ependymal cells in the adult spinal cord are latent progenitors that react to injury to support some degree of endogenous repair. Understanding the mechanisms by which these progenitor-like cells are regulated in the aftermath of spinal cord injury is critical to design future manipulations aimed at improving healing and functional recovery. Gap junctions and connexin hemichannels are key regulators of the biology of neural progenitors during development and in adult neurogenic niches. We find here that connexin signaling in the ependyma changes after injury of the adult spinal cord, functionally resembling the immature activestem cell niche of neonatal animals. Our findings suggest that connexins in ependymal cells are potential targets to improve self-repair of the spinal cord.

\section{Introduction}

The central canal (CC) is a latent stem cell niche whose cells may have retained part of the developmental programs needed to re-

Received Aug. 23, 2019; revised Jan. 20, 2020; accepted Jan. 23, 2020.

Author contributions: G.F., C.R., A.V.-K., and R.E.R. designed research; G.F., C.R., A.V.-K., M.I.R., J.F., and M.V.F. performed research;G.F., C.R., A.V.-K., M.I.R., J.F., M.V.F., and R.E.R. analyzed data;G.F., C.R., A.V.-K., M.I.R., J.F., and M.V.F. edited the paper; R.E.R. wrote the paper.

This work was supported by Wings for Life, Spinal Cord Research Foundation Grant WFL-UY-20/17 Project 167, Comisión Sectorial de Investigación Científica UdelaR Grant 538, and the Morton Cure Paralysis Fund to R.E.R. We thank Dr. Jonas Frisén for the generous gift of the FoxJ1CreER-tdTomato mice; Dr. Moa Stenudd for kind advice on the management of this transgenic mouse; Tabaré de los Campos for developing a macro to quantify connexin puncta; and Andrés Di Paolo for expert assistance in the acquisition of confocal images.

The authors declare no competing financial interests.

${ }^{*}$ G.F., C.R., and A.V.-K. contributed equally to this work. pair the spinal cord after traumatic injury (Göritz and Frisén, 2012; Sabelström et al., 2014). After spinal cord injury (SCI), ependymal cells resume their mitotic activity (Mothe and Tator, 2005; Cizkova et al., 2009) to play an important part in limiting the spread of the lesion by the contribution of cells to the glial scar and producing neurotrophic factors that promote the survival of neurons around the injury site (Sabelström et al., 2013). The manipulation of the ependymal stem cell niche to optimize the cellular events needed for endogenous repair requires understanding the mechanisms by which proliferation, migration, and

Correspondence should be addressed to Raúl E. Russo at rrusso@iibce.edu.uy or russoblanc@gmail.com. https://doi.org/10.1523/JNEUROSCI.2056-19.2020

Copyright $\odot 2020$ the authors 
differentiation of CC-contacting progenitors are regulated in the normal and injured spinal cord. In particular, it is important to explore the early functional changes induced by injury in CCcontacting progenitors.

Both in reptiles and neonatal rats, ependymal cells have heterogeneous membrane properties (Russo et al., 2008; Marichal et al., 2012), with voltage-gated $\mathrm{K}^{+}$currents that may regulate their behavior as described for some neural progenitors (Chittajallu et al., 2002; Schaarschmidt et al., 2009). In addition, some cells lining the CC are electrically and metabolically coupled via gap junctions (Russo et al., 2008; Marichal et al., 2012). Gap junction communication and connexin hemichannels are multifaceted regulators during the development and function of neural networks (Elias and Kriegstein, 2008). Indeed, connexins play an important role in the regulation of neural stem cells (Bruzzone and Dermietzel, 2006), with both connexin 43 (Cx43) and connexin 26 (Cx26) expressed differentially during development (Nadarajah et al., 1997; Bittman and LoTurco, 1999). The importance of connexins as regulators of proliferation is maintained in adult neurogenic niches as $\mathrm{KO}$ of $\mathrm{Cx} 30$ and $\mathrm{Cx} 43$ in progenitors of the dentate gyrus decrease their proliferation (Kunze et al., 2009). As early as $4 \mathrm{~h}$ after complete transection of the rat spinal cord, Cx43 mRNA increases and remains elevated at least 4 weeks after injury (Lee et al., 2005). The interference with Cx43 function after SCI reduces the reactive astrogliosis and neuronal death (O'Carroll et al., 2008) and improves functional recovery (Cronin et al., 2008). However, it is unknown whether connexins and gap junction coupling in the CC stem cell niche are regulated by injury. As postnatal development progresses, the ability of the spinal cord for self-repair declines and is paralleled by a reduction in the stem cell-like properties of ependymal cells, which become less competent to generate new oligodendrocytes (Li et al., 2016). The fact that progenitors contacting the lateral aspects of the neonatal CC have a higher proliferative rate (Marichal et al., 2012) suggests that coupling via connexins may be important to maintain an active CC stem cell niche. We hypothesized that membrane properties and/or communication via connexins in the $\mathrm{CC}$ are developmentally regulated and play a part in the reactivation of this latent stem cell niche after injury. To test these ideas, we combined patch-clamp recordings of ependymal cells in neonatal (P9-P11) and adult (P90-P150) mice with immunohistochemistry for various connexins in the normal and injured spinal cord. We found that coupling among ependymal cells was reduced in adulthood but increased after injury, resembling the immature CC. These changes were paralleled by an increase in the immunoreactivity of $\mathrm{Cx} 26$. In addition, we found that injury reduced the activity of connexin hemichannels in ependymal cells of the adult spinal cord. Finally, the pharmacological blockade of connexins reduced the injury-induced reactivation of ependymal cell proliferation. Collectively, our findings show that connexin signaling is involved in the early reaction of ependymal cells to injury and represents a potential target to improve the contribution of the CC stem cell niche to repair.

\section{Materials and Methods}

Animals. Neonatal (P9-P11) and adult (P90-P150) C57BL/6J mice were used. In some experiments, FoxJ1CreER-R26RtdTomato transgenic mice (gift from Prof. Jonas Frisén, Karolinska Institutet) were also used to facilitate the identification of ependymal cells. This transgenic mouse expresses CreER under the control of the FoxJ1 promoter, which is active in cells with motile cilia resulting in a selective and robust expression of tdTomato in ependymal cells (Meletis et al., 2008). To induce the expression of tdTomato in adult mice, we injected tamoxifen (Sigma Millipore;
$2 \mathrm{mg}, 20 \mathrm{mg} / \mathrm{ml}$ in corn oil, i.p.) for $5 \mathrm{~d}$ and allowed $5 \mathrm{~d}$ between the last injection and surgery to ensure clearance (Meletis et al., 2008). To induce recombination in neonatal animals, we applied 3 daily subcutaneous injections of tamoxifen (P4-P6) at a concentration of $75 \mu \mathrm{g} / \mathrm{g}$ of body weight (Cai et al., 2013). Pups were kept with their mother until use. All experimental procedures were approved by our local Committee for Animal Care (protocol \#006-5-2017).

SCI. Animals were anesthetized with ketamine ( $100 \mathrm{mg} / \mathrm{kg}$, i.p.), xylacine (10 mg/kg, i.p.), and diazepam ( $5 \mathrm{mg} / \mathrm{kg}$, i.p.). Injury of the dorsal aspect of the spinal cord was performed as described by Frisén et al. (1993). Briefly, after laminectomy, the dorsal funiculus at low thoracic level (T13) was cut transversely with microsurgical scissors (depth $\sim 0.8$ $\mathrm{mm}$ ), and the lesion was extended rostrally to comprise about one spinal cord segment. Recovery from anesthesia was promoted with flumazenil ( $0.5 \mathrm{mg} / \mathrm{kg}$, i.p.), yohimbine ( $2 \mathrm{mg} / \mathrm{kg}$, i.p.), and tramadol (3 mg/kg, i.p.) for pain relief. A second dose of tramadol was applied $24 \mathrm{~h}$ after surgery. Sham-injured animals were used as controls by performing all the procedures described above but without injuring the cord.

Slice preparation and electrophysiology. Neonatal mice were anesthetized with isoflurane (Forane, Abbott), whereas adult mice were anesthetized with ketamine (100 mg/kg, i.p.) and xylazine (10 mg/kg, i.p.). Immediately after achieving full unresponsiveness to painful stimuli, mice were decapitated and the thoracic spinal cord dissected out under cutting Ringer's solution (in mM as follows: NMDG, 92; $\mathrm{KCl}, 2.5$; $\mathrm{NaH}_{2} \mathrm{PO}_{4}, 1.5 ; \mathrm{NaHCO}_{3}, 30$; HEPES, 20; glucose, 25; thiourea, 2; Naascorbate, 5 ; Na-pyruvate, $3 ; \mathrm{CaCl}_{2}, 0.5 ; \mathrm{MgSO}_{4}, 10$; saturated with $5 \%$ $\mathrm{CO}_{2}$ and $95 \% \mathrm{O}_{2}, \mathrm{pH} 7.4$ ). Transverse 300 - $\mu \mathrm{m}$-thick slices were made in cutting Ringer's solution and then kept in resting Ringer's solution until use (in mM as follows: $\mathrm{NaCl}, 119 ; \mathrm{KCl}, 2.5 ; \mathrm{NaH}_{2} \mathrm{PO}_{4}, 1.5 ; \mathrm{NaHCO}_{3}, 26$; glucose, 12.5; thiourea, 2; Na-ascorbate, 5; Na-pyruvate, 3; $\mathrm{CaCl}_{2}, 2$; $\mathrm{MgSO}_{4}, 10$; saturated with $5 \% \mathrm{CO}_{2}$ and $95 \% \mathrm{O}_{2}$ to keep pH 7.4). In adult mice, the slices were incubated for $15 \mathrm{~min}$ at $34^{\circ} \mathrm{C}$ in the same cutting Ringer's solution (Peça et al., 2011) before storage in resting Ringer's solution. For recordings, slices were placed in a chamber and superfused at $1 \mathrm{ml} \mathrm{min}{ }^{-1}$ with Ringer's solution (in $\mathrm{mm}$ as follows: $\mathrm{NaCl}, 124 ; \mathrm{KCl}$, 2.4; $\mathrm{NaHCO}_{3}, 26 ; \mathrm{CaCl}_{2}, 2.4 ; \mathrm{MgSO}_{4} .6 \mathrm{H}_{2} \mathrm{O}, 1.3 ;$ HEPES, $1.25 ; \mathrm{KH}_{2} \mathrm{PO}_{4}$, 1.2; and glucose, 10; saturated with $5 \% \mathrm{CO}_{2}$ and $95 \% \mathrm{O}_{2}, \mathrm{pH} 7.4$ ). All experiments were performed at room temperature $\left(22^{\circ} \mathrm{C}-24^{\circ} \mathrm{C}\right)$. Cells were visualized with differential interference contrast optics (Leica Microsystems, DM LFS) or oblique illumination (Olympus, BX51WI) and patch-clamp whole-cell recordings obtained with electrodes filled with (in $\mathrm{mM}$ as follows: K-gluconate, $122 ; \mathrm{Na}_{2}$-ATP, $5 ; \mathrm{MgCl}_{2}, 2.5 ; \mathrm{CaCl}_{2}$, 0.003; EGTA, 1; Mg-gluconate, 5.6; K-HEPES, 5; H-HEPES, 5; and biocytin, 10; $\mathrm{pH} 7.3,5-10 \mathrm{M} \Omega$ ). To visualize recorded cells in living slices, Alexa-488 or -594 hydrazide (500 $\mu \mathrm{M}$, Invitrogen) was added to the pipette solution. Voltage-clamp recordings were performed with a Multiclamp 700B amplifier using pClamp10 (Molecular Devices). Seal resistances were between 1 and $4 \mathrm{G} \Omega$. In voltage-clamp mode, cells were held at $-70 \mathrm{mV}$, and the resting membrane potential (RMP) was estimated from the current-voltage relationship (at $\mathrm{I}=0$ ). To subtract leak currents, we used a $\mathrm{P} 4$ protocol by Clampex10 (Molecular Devices). Liquid junction potentials were determined and corrected offline (Barry, 1994).

Morphological identification of patch-clamp recorded cells. During whole-cell patch-clamp recordings, cells were filled with a fluorophore and biocytin. Cells were first imaged in living slices by epifluorescence; and after completion of the recording period, slices were fixed by immersion in $4 \% \mathrm{PFA}$ in $0.1 \mathrm{M} \mathrm{PB}, \mathrm{pH} 7.4$, overnight. Following $\mathrm{PB}$ rinsing, the slices were incubated in $\mathrm{PB}$ containing $0.3 \%$ Triton $\mathrm{X}-100$ with streptavidin-Alexa-488 or -546 (1:200; Invitrogen, Thermo Fisher Scientific), mounted in glycerol, and imaged in a confocal microscope (Olympus, VF300; or Carl Zeiss, LSM800 Airyscan).

Immunohistochemistry. Animals were anesthetized with ketamine (100 $\mathrm{mg} / \mathrm{kg}$, i.p.), xylacine (10 mg/kg, i.p.), and diazepam ( $5 \mathrm{mg} / \mathrm{kg}$, i.p.) and fixed by intracardiac perfusion with $4 \% \mathrm{PFA}$ in $0.1 \mathrm{M} \mathrm{PB}$. The following primary antibodies were used: anti-Cx43 (rabbit polyclonal, 1:500; Alomone Labs, \#ACC-201), anti-Cx26 (rabbit polyclonal, 1:200; Alomone Labs, \#ACC-212), anti-Cx30 (rabbit polyclonal, 1:500; Thermo Fisher Scientific, \#71-2200), anti-Cx50 (mouse monoclonal, 1:3000, Thermo Fisher Scientific, \#33-4300), and anti-Iba1 (rabbit polyclonal, 1:1600, 
Wako Chemicals, \#019-19741). The spinal cord was sectioned with a vibrating microtome $(60-80 \mu \mathrm{m}$ thick), placed in $\mathrm{PB}$ with $0.5 \%$ BSA for $30 \mathrm{~min}$, and then incubated with primary antibodies in $\mathrm{PB}$ with $0.3 \%$ Triton X-100 (Sigma Millipore). Anti-Ibal was dissolved in PBS with $1 \%$ Triton X-100 and $10 \%$ FBS for $48 \mathrm{~h}$ at $4^{\circ} \mathrm{C}$. Sections were then incubated in secondary antibodies conjugated with different fluorophores or HRP. Nuclei were stained with DAPI (Invitrogen). Control experiments were performed suppressing primary antibodies.

5-Ethynyl-2-deoxyuridine (EdU) proliferation assay. EdU $(40 \mathrm{mg} / \mathrm{kg}$, i.p.) was injected twice daily ( 4 h interval) from day 3 to day 5 after SCI. The animals were anesthetized as already described at day 5 after injury and perfused with $4 \%$ PFA in $0.1 \mathrm{M} \mathrm{PB}, \mathrm{pH}$ 7.4. EdU was revealed with the Click-iT AlexaFluor-647 imaging kit (Invitrogen, Thermo Fisher Scientific).

Connexin hemichannel permeability assay. The activity of connexin hemichannels in ependymal cells was evaluated by the uptake of the hemichannel permeable dye ethidium bromide (EtBr; $4 \mu \mathrm{M}, 15 \mathrm{~min}$ ). Briefly, spinal cord slices were cut as described above and incubated in Ringer's solution devoid of calcium 15 min before and during the application of EtBr with or without the application of the broad connexin blocker carbenoxolone (Cbx; $200 \mu \mathrm{M})$, the cell-permeant $\mathrm{Cx} 43$ hemichannel blocking peptide TAT-Gap19 (YGRKKRRQRRR-KQIEIKKFK, $100 \mu \mathrm{M}$ ), or the control peptide TAT-Gap19scrambled (YGRKKRRQRRRIEKFKIKQK, $100 \mu \mathrm{M}$ ). After incubation in these solutions, slices were rinsed in normal Ringer's solution for $15 \mathrm{~min}$, then fixed for $24 \mathrm{~h}$ in $4 \%$ PFA in $\mathrm{PB}, \mathrm{pH} 7.4$, rinsed in $\mathrm{PB}$ ( 3 times, $10 \mathrm{~min}$ ), and finally mounted in glycerol for imaging. Ependymal cells were imaged in an LSM800 Airyscan confocal microscope (Carl Zeiss). Stacks of consecutive confocal images with high-bit depth color (16 bit) were taken at $1 \mu \mathrm{m}$ intervals with the $561 \mathrm{~nm}$ laser for $\mathrm{EtBr}$ at 2.5\% of laser intensity and detector settled at $743 \mathrm{~V}$. Dye uptake analysis was performed in an ROI defined by the outline of the ependyma. As described by Chever et al. (2014), fluorescence intensity was digitized in arbitrary units of 65,000 shades of gray with ImageJ (National Institutes of Health) (Schneider et al., 2012). EtBr uptake (as fluorescence units) was expressed as the difference between the fluorescence measured in ependymal cells ( $\sim 75$ cells per slice) and the background fluorescence from a field with no labeled cells.

In vivo blockade of connexins in the injured spinal cord. To locally block signaling via connexins around the lesion epicenter, $50 \mu$ l of Pluronic F127 $\left(20 \% \mathrm{w} / \mathrm{v}\right.$ in saline at $\left.5^{\circ} \mathrm{C}-10^{\circ} \mathrm{C}\right)$ containing the connexin blocking peptide Gap26 (10 mm, VCYDKSFPISHVR, GenScript) was injected within the lesion. The liquid Pluronic F127, kept at low temperatures, easily filled the lesion site and became a hydrogel as warmed up in contact with the tissue. Pluronic F127 dissolved in saline or containing the scrambled version of Gap26 (Gap26Scr, PSFDSRHCIVKYV, GenScript) was injected within the injured spinal cord as controls.

Experimental design and statistical analyses. Mice of either sex were randomly assigned to experimental groups. Sham-injured mice were used as controls. When using injured mice, we checked that loss of weight at death did not exceed $15 \%$. The following criteria were used for including the data from patch-clamp experiments: a stable holding current, an RMP more hyperpolarized than $-40 \mathrm{mV}$, and an access resistance $\leq 40$ $\mathrm{M} \Omega$. At least a $10 \mathrm{~min}$ control period with stable electrophysiological properties was allowed before drug application. Electrophysiological data were analyzed with Clampfit 10.0 (Molecular Devices). All images obtained for quantitative analysis were taken using the same preset parameters and analyzed with ImageJ. For quantitative analysis of immunofluorescence data, a minimum of five sections were analyzed and averaged per biological replicate ( 5 animals for each experimental condition, unless otherwise stated). To analyze the expression of connexins in the apical and basal portions of ependymal cells, the immunoreactive puncta were converted into particles using a macro developed in IJ1macro language (ImageJ, National Institutes of Health) and quantified in two regions: an inner ring $(0-5 \mu \mathrm{m}$ from the CC lumen) and an outer ring (5-20 $\mu \mathrm{m}$ from the CC lumen). The confocal images were acquired with an LSM800 Airyscan confocal microscope (Carl Zeiss). Statistical analyses were performed with Prism 7.0 (GraphPad). Statistical significance was set at $p<0.05$. The statistical test chosen for different experiments is noted next to the corresponding result. Numerical values are reported as mean \pm SEM.

\section{Results}

Neural progenitors have membrane properties that regulate their behavior. For example, voltage-gated $\mathrm{K}^{+}$channels (Chittajallu et al., 2002; Pardo, 2004; Schaarschmidt et al., 2009) and gap junction coupling via connexins (Bruzzone and Dermietzel, 2006) have been shown to affect the ability of neural stem cells to proliferate. Ependymal cells in the spinal cord of neonatal rodents are functionally heterogeneous with some displaying complex electrophysiological phenotypes (Marichal et al., 2012). Thus, we asked whether the membrane properties of ependymal cells vary as the CC matures to become quiescent. To address this question, we made patch-clamp recordings of ependymal cells in acute spinal cord slices of neonatal (P9-P11) and adult (P90-P150) mice. The membrane properties of ependymal cells in neonatal animals were dominated by prominent leak currents (Fig. $1 A, B$ ) with input resistances (IRs) of $116.8 \pm 11.3 \mathrm{M} \Omega(n=48)$ and RMP of $-79.0 \pm 1.3 \mathrm{mV}(n=48)$. Leak subtraction allowed the discrimination of two cell types: Type 1 cells with a passive electrophysiological phenotype (Fig. $1 A ; n=25$ ) and Type 2 cells with sizable outward currents (Fig. $1 B ; n=11$ ). In a few recordings, a small inward current was observed $(n=4$, data not shown).

The electrophysiological phenotypes of ependymal cells in the lateral domains of the $\mathrm{CC}$ of adult mice were similar from those in neonatal animals (Fig. $1 C-E)$ with IR of $109.0 \pm 18.1 \mathrm{M} \Omega(n=$ $36)$ and RMP of $-77 \pm 1.83 \mathrm{mV}(n=36)$. There were no statistically significant differences of the IR (Fig. $1 F_{1}$ ) and RMP (Fig. $1 F_{2}$ ) between ependymal cells from neonatal and adult mice ( $p=$ 0.20 and $p=0.97$, respectively; Mann-Whitney $U$ test). In addition, the relative frequency of Type 1 (passive; Fig. 1C) and Type 2 (with noninactivating and inactivating outward currents; Fig. $1 D, E)$ cells was not statistically different $(p=0.58$, Fisher's exact test; Fig. $1 G$ ).

Our previous study in neonatal rats showed that most cells in the lateral domains of the $\mathrm{CC}$ are coupled via gap junctions (Marichal et al., 2012). Thus, we assessed gap junction coupling among ependymal cells by injection of biocytin, which permeates through functional gap junctions revealing dye coupling. As expected, most recordings of ependymal cells (47 of 68) in the lateral domains of the neonatal CC revealed clusters of dye-coupled cells (Fig. 2A-C). The morphology of clusters of dye-coupled cells was heterogeneous, with some covering a substantial portion of the CC (Fig. $2 A$, right, insets, $B_{2}, C_{1}, C_{2}$ ) and some comprising most of the lateral aspect of the CC (Fig. $2 B_{3}$ ), whereas others were limited to a narrower extension (Fig. $2 B_{1}$ ). Both the counterstaining with DAPI (Fig. $2 A$, insets, $B_{3}$ ) and recombination of the reporter gene tdTomato in ependymal cells of FoxJ1CreER mice (Fig. $2 B_{1}, B_{2} ; \sim 60 \%$ of the whole ependymal cell population) (Meletis et al., 2008) confirmed that the cell bodies of dye-coupled cells were confined to the ependymal cell layer. Some cells within the clusters had processes that gathered to form a bundle projecting to the dorsal (Fig. $2 A$, arrowheads, $C_{1}$, arrowheads) or the ventral (Fig. $2 C_{2}$, arrowheads) raphe. As expected for ependymal cells, a careful inspection of the apical surface of dye-coupled cells revealed a variable number of cilia projecting to the CC lumen (Fig. 2A, bottom left, inset; Movie 1). The gap junction blocker Cbx $(100 \mu \mathrm{M})$ increased the IR (Fig. $2 D_{1} ; p<$ 0.05 ; Wilcoxon matched pairs signed rank test, $n=6$ ), indicating that dye coupling resulted from gap junction coupling. Because Cbx has been reported to interact with targets other than connex- 

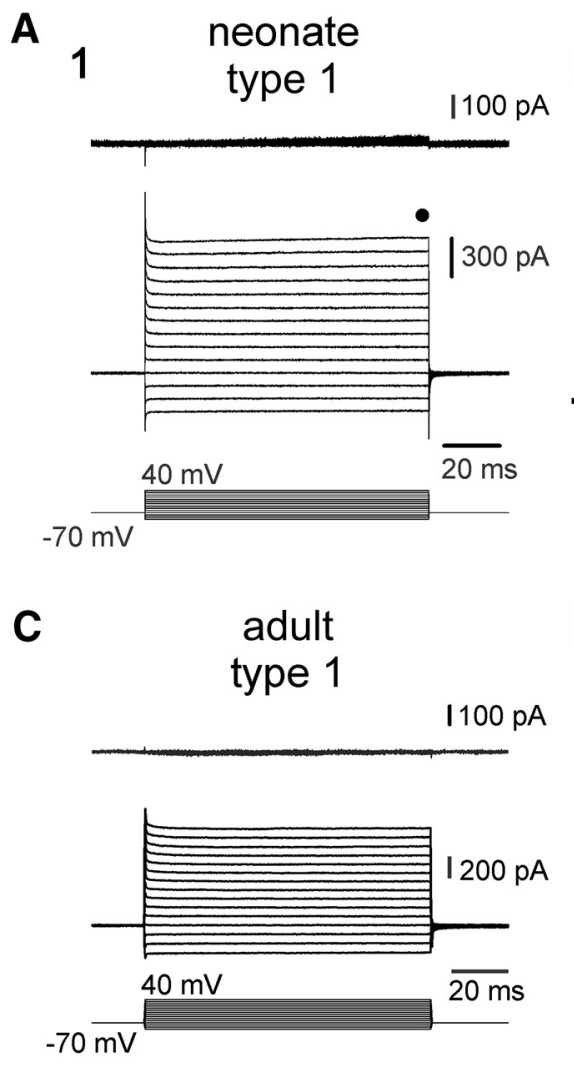

\section{2}

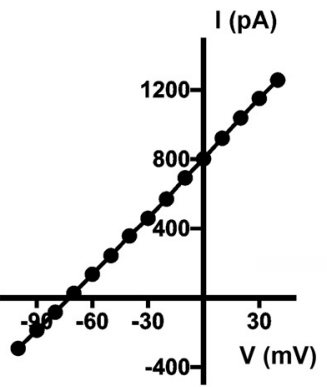

B
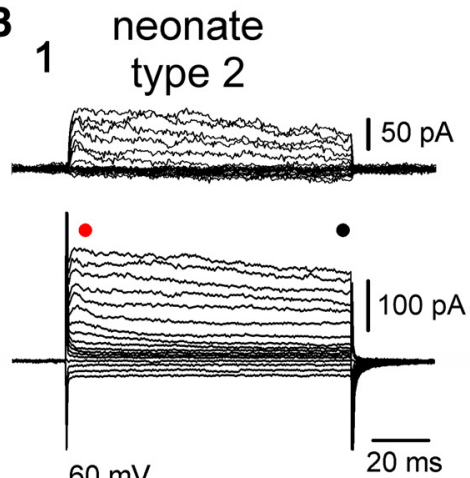

$60 \mathrm{mV}$

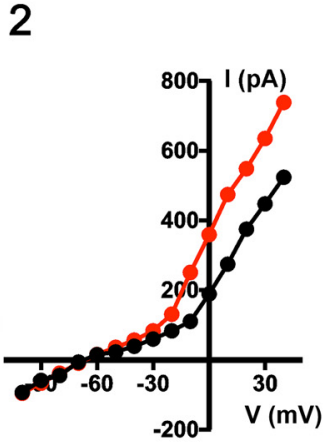

$-70 \overline{\mathrm{mV}}$

D
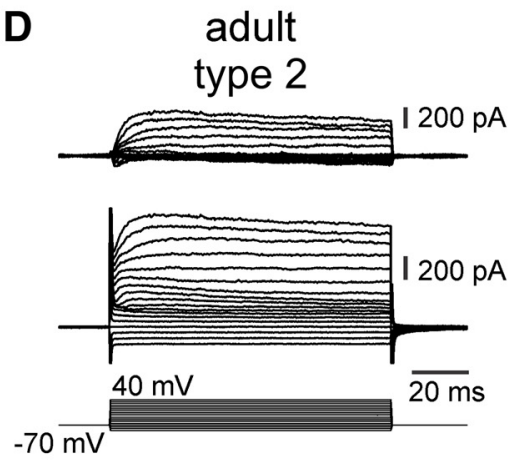

$\mathbf{F}$

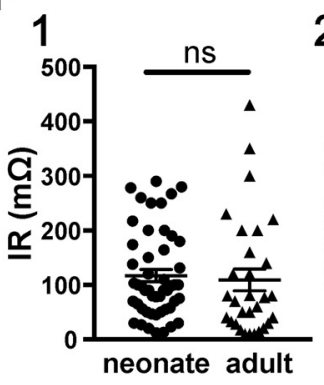

2

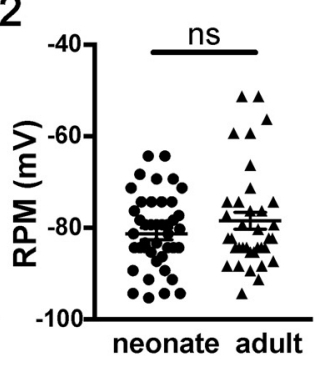

E

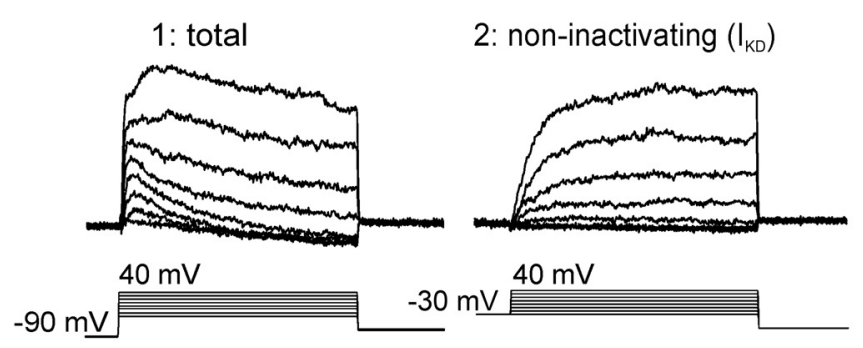

1-2: inactivating $\left(I_{A}\right)$

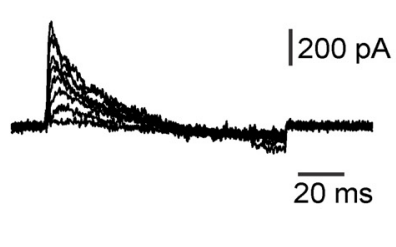

G

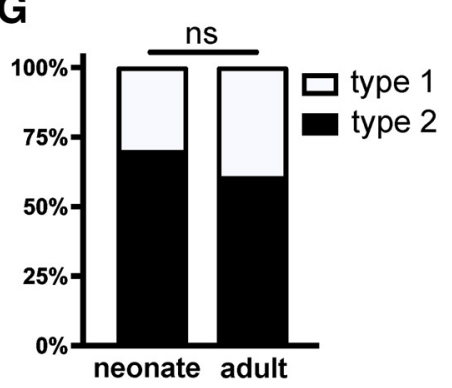

Figure 1. Electrophysiological properties of ependymal cells in the neonatal and adult spinal cord of mice. $A$, Currents induced by a series of voltage steps applied to an ependymal cell on the lateral domain of the $C\left(A_{1}\right)$ of a neonate mouse. The leak-subtracted currents $\left(A_{1}\right.$, top) and the $I-V$ plot $\left(A_{2}\right)$ show that the response to voltage steps was completely passive (Type 1 cell). $\boldsymbol{B}$, $A$ subpopulation (Type 2 ) of ependymal cells in the neonatal spinal cord displayed voltage-gated outward currents $\left(\boldsymbol{B}_{1}\right)$. The $I-V$ plot in Type 2 cells is nonlinear $\left(\boldsymbol{B}_{2}\right)$. The current plots at the beginning (red dots) and the end (black dots) suggest that voltage-gated outward currents have a component with time- and voltage-dependent inactivation. $\boldsymbol{C}, \boldsymbol{D}$, The electrophysiological phenotypes of ependymal cells in the adult spinal cord ( $P>90)$ were similar to their neonatal counterpart with Type 1 passive cells $(\boldsymbol{C})$ and Type 2 cells $(\boldsymbol{D})$. $\boldsymbol{E}$, Current responses to voltage steps applied from a holding potential of $-90 \mathrm{mV}\left(\boldsymbol{E}_{1}\right)$ and $-30 \mathrm{mV}\left(\boldsymbol{E}_{2}\right)$ in an ependymal cell of the adult spinal cord. Notice the slow kinetics and lack or inactivation of the outward currents from a holding potential of $-30 \mathrm{mV}$ typical of a delayed rectifier $\left(I_{\mathrm{KD}}\right)$. Subtraction of currents at -90 and $-30 \mathrm{mV}$ reveals a fast inactivating component characteristic of A-type $\left(I_{A}\right)$ currents. $F$, No statistically significant differences were found for the IRs $\left(\boldsymbol{F}_{1}, p=0.29\right)$ and $\operatorname{RMPs}\left(\boldsymbol{F}_{2}, p=0.3\right)$ between neonate and adult ependymal cells. $\boldsymbol{G}$, Ratio of Type 1 and Type 2 cells in neonate and adult ependyma. ns, non significant.

ins (e.g., $\mathrm{GABA}_{\mathrm{A}}$ receptors and calcium channels among others) (Juszczak and Swiergiel, 2009; Connors, 2012), we also tried the more specific peptidic antagonist Gap26 (Evans et al., 2012). In line with the results obtained with Cbx, Gap26 also increased the IR of cells that were dye-coupled with neighboring cells (Fig. 2D ; $p<0.05$, Wilcoxon matched pairs signed rank test, $n=7$ ). In a minority of cases, patch-clamp recordings in the CC of neonatal animals resulted in single labeled cells (Fig. 2E). However, the situation in the adult CC was different. Figure $2 F$ shows the morphology of a patch-clamped single ependymal cell with two conspicuous cilia protruding into the CC lumen. Although clusters of dye-coupled cells in the CC of the normal adult mouse could be observed (Fig. 2G,H), the relative frequency of clusters of gap junction-coupled cells was significantly lower than in the immature spinal cord ( 15 of 56; Fig. 2I; $p<0.0001$, Fisher's exact test). However, the mean volume of clusters of gap junction-coupled cells was not significantly different between neonatal and adult animals (Fig. 2J; $p=0.40$, Mann-Whitney $U$ test). Both in neonatal and adult mice, clusters of gap junction-coupled cells often surrounded other ependymal cells that were not dye-coupled (Fig. $2 B_{2}, G$, inset, arrowheads; Movie 2). Regardless the age, the electrophysiological phenotypes of single cells were not statistically different from clustered cells $(p=0.91$, Fisher's exact test).

To explore the molecular basis of gap junction coupling in the $\mathrm{CC}$ and whether there is some developmental plasticity, we made 

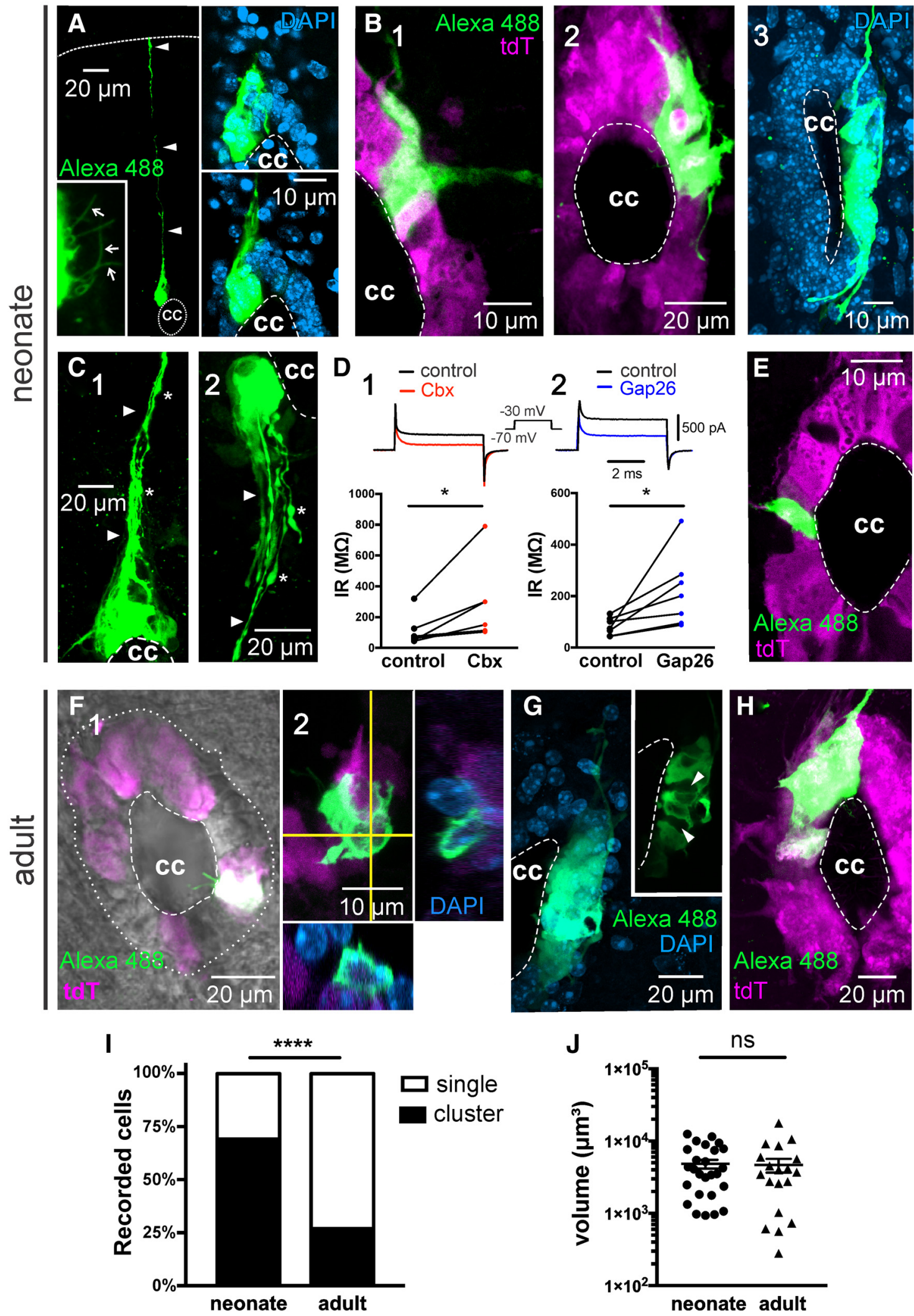

Figure 2. Gap junction coupling between ependymal cells is developmentally downregulated. $A$, Cluster of dye-coupled cells contacting the CC in the neonatal spinal cord (stack of 58 confocal optical sections). Some cells in the cluster had processes that project to the dorsal raphe, reaching the pia matter (arrowheads). Several cilia (bottom left, inset, arrows) are seen on the apical pole of clustered cells (stack of sections 12-21). Right, Insets, Two confocal optical sections with DAPI counterstaining to illustrate that dye-coupled cells are within the ependymal cell layer. $\boldsymbol{B}$, Clusters of dye-coupled cells cover variable portions of the $C\left(. B_{1}\right.$, A small cluster of dye-coupled cells comprising a discrete extension of the dorsolateral aspect of the $C\left(B_{2}, A\right.$ cluster covering the dorsolateral half of the CC (stack of 64 optical sections). Some dye-coupled cells covered the whole lateral aspect of the CC ( $\boldsymbol{B}_{3}$, stack of 86 optical sections). $\boldsymbol{C}$, Clustered cells often showed processes (arrowheads) that projected toward the dorsal $\left(\boldsymbol{C}_{1}\right)$ or ventral $\left(\boldsymbol{C}_{2}\right)$ raphe (stacks of 43 and 60 optical sections, respectively). Numerous varicosities $\left(\boldsymbol{C}_{1}, \boldsymbol{C}_{2}\right.$, asterisks) could be observed at some distance of the $\boldsymbol{C C}$. $\boldsymbol{D}_{1}$, Cbx (100 $\left.\mu \mathrm{M}\right)$ and Gap26 $\left(\boldsymbol{D}_{2}, 200 \mu \mathrm{M}\right)$ increased the IR in cells that were dye-coupled to their neighbors. Top, Representative currents induced by a voltage (Figure legend continues.) 


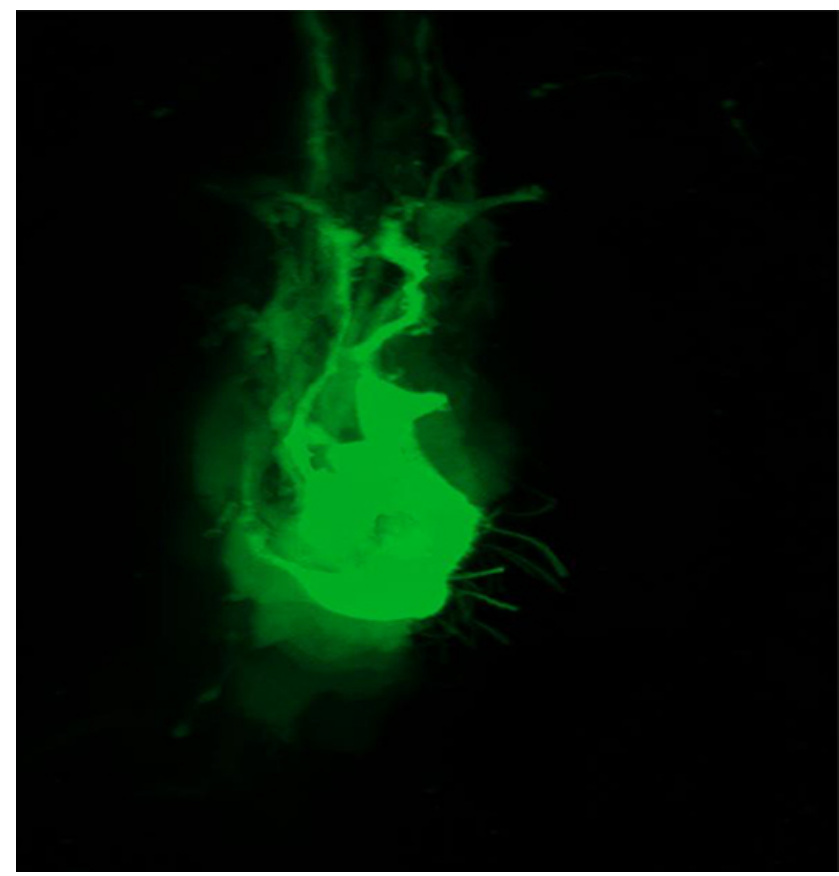

Movie 1. 3D reconstruction of a cluster of dye-coupled cells. The movie shows a large cluster of cells with a core that is intensively dye-coupled surrounded by an outer group of fainter cells (probably due to a lower coupling coefficient). Notice a number of cilia arising from the apical pole of clustered cells. Data obtained from a C57BL/6J mouse. [View online].

immunohistochemistry for various connexins in neonatal and adult mice. Similar to the developing cortex (Dermietzel et al., 1989; Nadarajah et al., 1997) and the CC in turtles (Russo et al., 2008), we found that $\mathrm{Cx} 43$ and $\mathrm{Cx} 26$ were expressed in ependymal cells of the CC of neonatal mice (Fig. $3 A, B$ ). Because Cx30 is expressed in astrocytes (Rash et al., 2001) and ependymal cells in the brain (Kunzelmann et al., 1999), we asked whether ependymal cells express Cx30 in addition to $\mathrm{Cx} 43$ and Cx26. In neonatal mice, we found a very weak immunostaining for Cx30 with few scattered puncta in the gray and white matter, whereas ependymal cells lining the CC were devoid of $\mathrm{Cx} 30$ (Fig. 3C). Cx43 was also strongly expressed in the CC of the adult spinal cord with a similar spatial profile than in neonatal animals (Fig. 3D). However, unlike in the neonatal CC, the immunoreactivity for Cx26 was very low in ependymal cells of the adult spinal cord (Fig. 3E). Whereas Cx30 in the neural parenchyma increased substantially in the spinal cord of adult mice, the ependymal cell layer remained devoid of $\mathrm{Cx} 30$ (Fig. 3F). Despite that Cx50 has been reported in ependymal cells isolated from the spinal cord of rats (Rodríguez-Jimenez et al., 2016), we found no immunoreactivity

(Figure legend continued.) step from -70 to $-30 \mathrm{mV}$ before and after the gap junction blockers. $\boldsymbol{E}$, A minority of recordings in the ependyma of neonate mice revealed single cells (stack of 8 optical sections). $\boldsymbol{F}$, Ependymal cell in the adult CC $\left(\boldsymbol{F}_{\boldsymbol{1}}\right)$. The cell had two conspicuous cilia. Orthogonal projections combined with DAPI staining confirm that the image corresponds to a single tdTomato ${ }^{+}$cell $\left(\boldsymbol{F}_{2}\right)$. Stack of 28 optical sections. $\boldsymbol{G}$, In a few cases, the recorded cells in the adult ependyma was part of a cluster of gap junction-coupled cells (stack of 38 optical sections). Inset, The single optical plane shows that the cluster engulfed ependymal cells that were not coupled (arrowheads). $\boldsymbol{H}$, Cluster of dye-coupled cells in the adult spinal cord of a FoxJ1CreER-tdTomato mouse (stack of 39 optical sections). I, Plot represents that the incidence of coupling was significantly lower in the adult CC ( $p<0.0001)$. J, The volume of clusters of dye-coupled cells in the neonate and adult CC was not significantly different ( $p=$ 0.40). $\boldsymbol{A}, \boldsymbol{B}_{\mathbf{3}}, \boldsymbol{C}, \boldsymbol{G}$, Data obtained from (57BL/6J mice. In this and subsequent figures, dorsal is facing upward. ${ }^{*} p<0.05,{ }^{* * *} p<0.0001$, ns $=$ non significant.

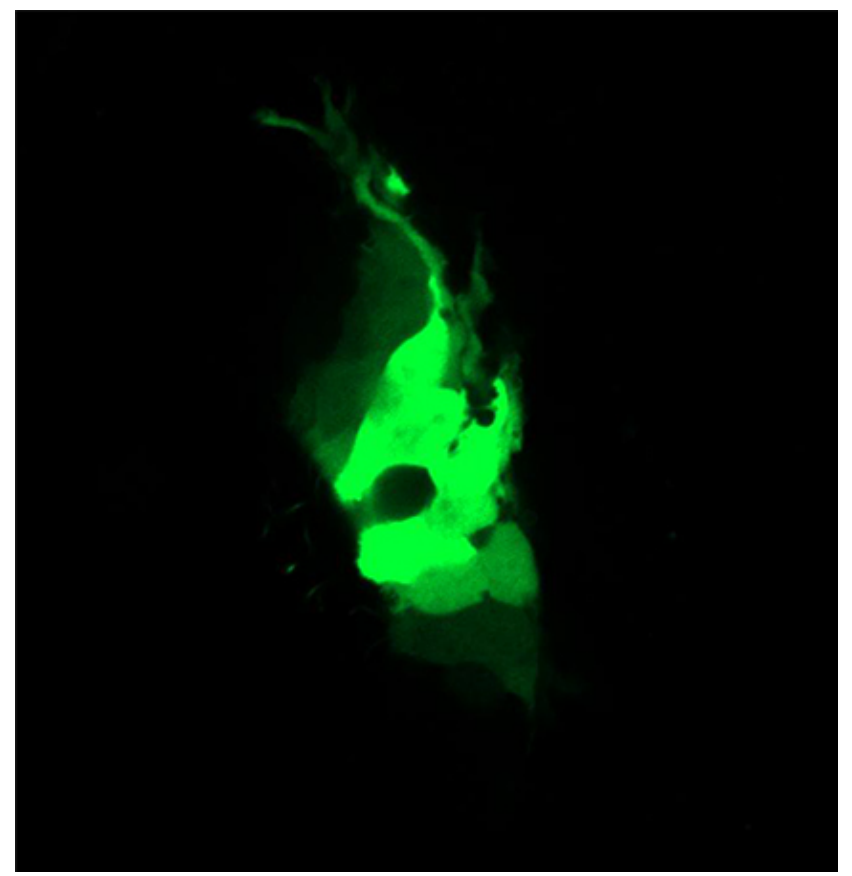

Movie 2. Sequence of optical sections in the $z$ axis of a cluster of dye-coupled cells. Notice some "ghost" cells (asterisks) that are engulfed by the cluster of gap junction-coupled cells Same cluster as shown in Movie 1. [View online]

within the ependymal cell layer of neonatal or adult mice (data not shown).

In turtles, $\mathrm{Cx} 43$ is spatially segregated to the apical compartment of ependymal cells (Russo et al., 2008). To explore the relative distribution of $\mathrm{Cx} 43$ and $\mathrm{Cx} 26$ in the apical and basal compartments of ependymal cells, we digitally converted connexin puncta into particles and quantified their density in two concentric rings $(0-5 \mu \mathrm{m}$ and 5-20 $\mu \mathrm{m}$ from the CC lumen; Fig. $3 G)$. Although Cx43 puncta were expressed at different distances from the CC lumen, a statistically significant higher density of puncta was observed in the apical poles of ependymal cells close to CC lumen in neonatal but not in adult mice (Fig. $3 H ; p<0.05$ and $p=0.079$, respectively, two-way ANOVA with Holm-Sidak post hoc, $n=5$ animals per group). The overall density (apical + basal compartments) of $\mathrm{Cx} 43$ puncta in neonatal and adult mice did not change significantly (Fig. $3 H ; p=0.072$, two-way ANOVA). In contrast to $\mathrm{Cx} 43$, the densities of $\mathrm{Cx} 26$ in the apical and basal compartments of ependymal cells of the neonatal and adult spinal cord were not significantly different (Fig. 3I; $p=0.16$ and $p=$ 0.93, respectively, two-way ANOVA with Holm-Sidak post hoc, $n=5$ animals per group). As suggested by the representative images shown in Figure $3 B, E$, the density of $\mathrm{Cx} 26$ puncta in the adult ependyma was greatly reduced compared with their neonatal counterpart (neonatal: $7.2 \pm 1.4$ puncta/100 $\mu \mathrm{m}^{2}$; adult: $1.00 \pm 0.5$ puncta $/ 100 \mu \mathrm{m}^{2}$, Fig. $3 I ; p<0.0001$, two-way ANOVA).

Gap junction coupling has been shown to be important for the maintenance of the phenotype of active progenitor cells (Cheng et al., 2004; Bruzzone and Dermietzel, 2006). The low rate of gap junction coupling among ependymal cells may be related to the very low proliferative activity of this stem cell niche in adulthood (Alexovic Matiasová et al., 2017). Thus, we speculated that reactivation of "dormant" progenitor-like cells in the CC by injury (Mothe and Tator, 2005; Meletis et al., 2008) may correlate with an increase in gap junction coupling. To test this idea, we per- 
formed a dorsal hemisection of the spinal cord and made patch-clamp recordings of ependymal cells 5 days post injury (DPI) in slices cut from the rostral and caudal stumps ( $1.2 \mathrm{~mm}$ at both sides of the lesion epicenter; Fig. 4A). We found no statistically significant differences between the RMP of ependymal cells from injured and sham-injured mice (Fig. $4 B_{1}$; RMP-injured: $-78.6 \pm 3.48 \mathrm{mV}, n=15$; RMP sham: $-76.0 \pm 2.77, n=11 ; p=0.54$, Mann-Whitney $U$ test). However, the IR was lower in cells recorded in the injured spinal cord (Fig. 4B ; IR-injured: $57.35 \pm$ $9.4 \mathrm{M} \Omega, n=17$; IR sham: $155.4 \pm 40.4$ $\mathrm{M} \Omega, n=11 ; p<0.05$, Mann-Whitney $U$ test). We found no differences on the relative frequency of cells with passive membrane properties (Type 1) and those with voltage-gated outward currents (Type 2) (Fig. $4 B_{3} ; p=0.66$, Mann-Whitney $U$ test). Whereas intracellular biocytin staining still revealed some single ependymal cells (Fig. 4C), the frequency of clusters of dye-coupled cells over single cells in injured animals compared with sham controls was significantly higher (Fig. 4D-F; $p<0.01$, Fisher's exact test, 38 of 56 and 15 of 37 , respectively). The relative frequency of clusters of gap junctioncoupled cells in adult injured animals was comparable with that of normal neonatal animals (Figs. $2 I, 4 F ; p=0.83$. Fisher's exact test), and there was no statistically significant difference between the incidence of clusters between normal and sham-injured adult mice ( $p=0.35$, Fisher's exact test). We then asked whether the increase in the relative frequency of gap junction coupling among ependymal cells in the lateral domains of the CC may be associated with a larger size of clusters of gap junction-coupled cells. To answer this question, we made $3 \mathrm{D}$ reconstructions of the clusters of gap junction-coupled cells and calculated the total volume (in $\mu \mathrm{m}^{3}$ ) using ImageJ (Fig. 4G). We found no significant differences between the average size of clusters between injured and shaminjured adult animals (Fig. $4 G ; p=0.48$, Mann-Whitney $U$ test).

Next, we explored the molecular basis for the upregulation of gap junction coupling induced by SCI. The overall density and location of $\mathrm{Cx} 43$ puncta within the ependymal cell layer were not different in the spinal cord stumps $(0-2000 \mu \mathrm{m}$ from the lesion epicenter) of the injured compared with sham control animals (Fig. $5 A-C ; p=0.26$, two-way ANOVA). In contrast to $\mathrm{Cx} 43$, the expression of $\mathrm{Cx} 26$, which was low in the intact adult CC (Fig. $3 E$ ) and in sham-injured controls (Fig. 5D), increased significantly within the ependymal cell layer of injured animals (Fig. $5 E, F ; p<$ 0.01, Kruskal-Wallis test with Dunn's post hoc), resembling the immunostaining for Cx26 in neonatal mice (Fig. $3 B$ ). As in the normal spinal cord, there was no immunoreactivity for $\mathrm{Cx} 30$ and neonate
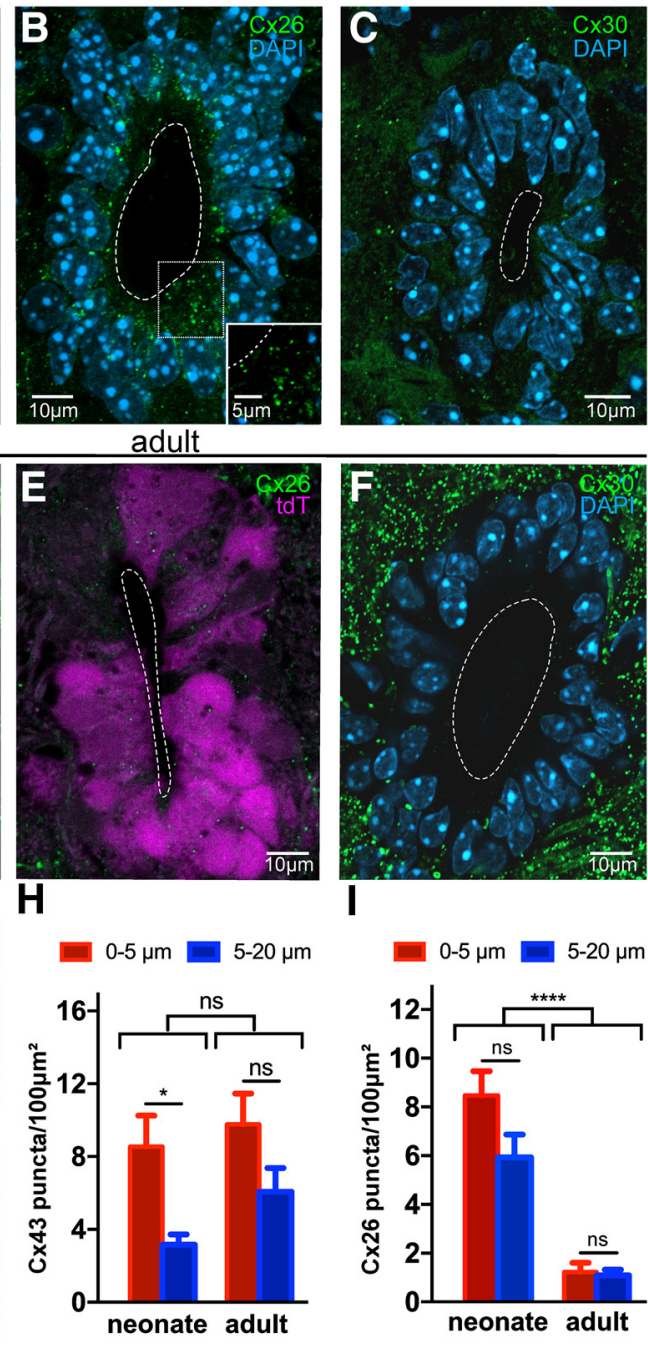

Figure 3. Molecular basis of gap junction coupling in the neonatal and adult CC. $A$, Immunoreactivity for $\mathrm{Cx} 43$ in the CC of neonatal mice. Cx43 is expressed at a higher density in the apical pole of ependymal cells. $\boldsymbol{B}, \mathbf{C} 26$ puncta are abundant in the immature CC. Inset, small Cx26 puncta from the boxed region are shown at higher magnification. C, Cx30 puncta are scarce in

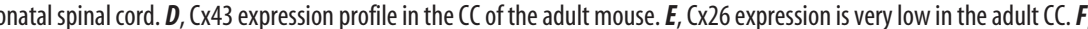

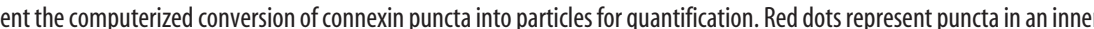
from (C lumen), and blue dots represent an outer ring (5-20 $\mu \mathrm{m}$ from CC lumen) of the ependymal cell layer. in neonatal but not in adult mice ( $p<0.05$ and $p=0.079$, respectively). $I$, The overall density of (x26 puncta in the CC mato. $\boldsymbol{A}-\boldsymbol{C}, \boldsymbol{F}$, Data obtained in $\left(57 \mathrm{BL} / 6 \mathrm{~J}\right.$ mice. All images represent single confocal optical sections. ${ }^{*} p<0.05,{ }^{* * *} p<0.0001$ $\mathrm{ns}=$ non significant. In this and subsequent figures, error bars indicate SEM.

Cx50 in the ependymal cell layer of the rostral and caudal stumps of the injured cord at 5 DPI (data not shown).

A hallmark of the reactive CC is that ependymal cells resume mitotic activity (Mothe and Tator, 2005). Thus, we compared the spatial profile of the proliferative reaction of ependymal cells in the CC with that of the increased expression of $\mathrm{Cx} 26$ at 5 DPI. The thymidine analog EdU was injected twice daily ( $40 \mathrm{mg} / \mathrm{kg}$, i.p.) from day 3 to day 5 after injury (Fig. $5 G_{1}, G_{2}$ ). EdU ${ }^{+}$nuclei in the CC peaked around the lesion epicenter (Fig. $5 \mathrm{H}_{2}, \mathrm{I}$ ) to reach control levels at $\sim 2000 \mu \mathrm{m}$ away from the lesion site (Fig. $5 \mathrm{H}_{1}-\mathrm{H}_{3}, I$ ). The spatial profile of the increased expression of $\mathrm{Cx} 26$ was slightly wider than for EdU uptake (Fig. 5I). There was a signifi- 
A

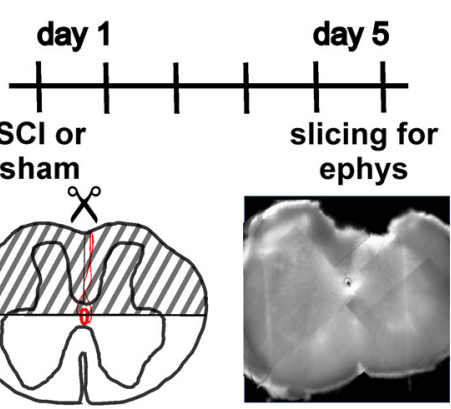

$\mathbf{B}_{1}$

2

3 -
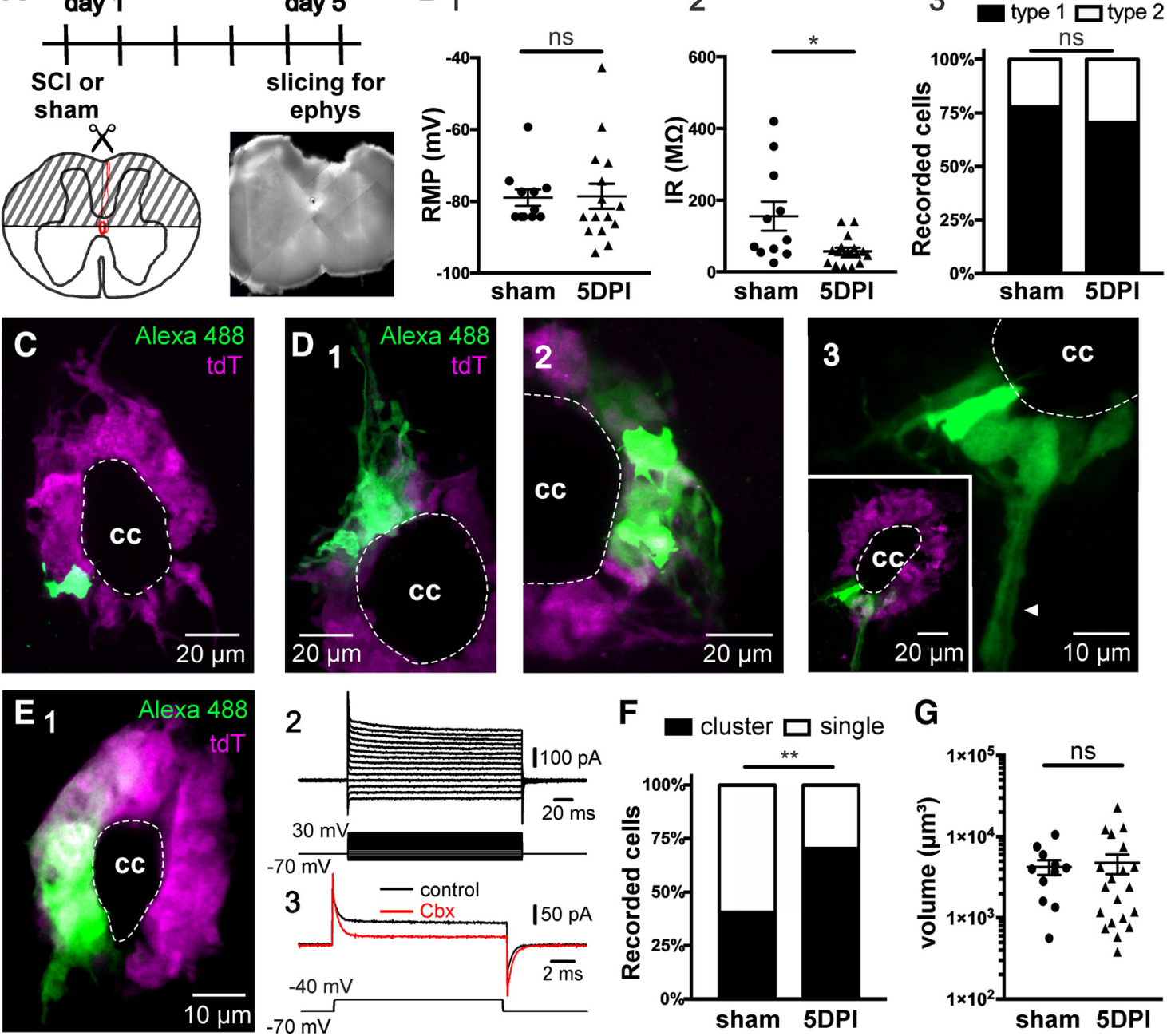

G

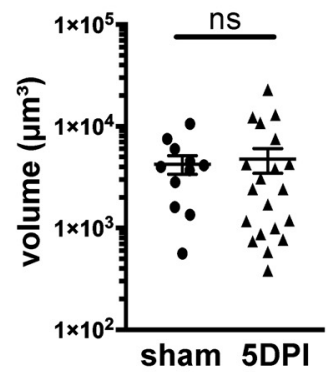

Figure 4. Injury increases gap junction coupling between ependymal cells of the adult spinal cord. $A$, Experimental design to search for plasticity of ependymal cell functional properties in early stages after injury. Bottom right, Collage of a living spinal cord slice at 5 DPI. $\boldsymbol{B}, \operatorname{RMP}\left(\boldsymbol{B}_{1}, \mathrm{RMP}\right), \mathrm{IR}\left(\boldsymbol{B}_{2}, \mathrm{R}\right)$, and ratio of Type 1 and Type 2 cells $\left(\boldsymbol{B}_{3}\right)$ in ependymal cells from sham-injured (sham) and injured (5 DPI) adult spinal cord. The IR between the two groups was significantly different $(p<0.05)$, whereas both the RMP and the proportion of Type 1 and Type 2 cells were not. $\boldsymbol{C}$, Single ependymal cell recorded at 5 DPI (stack of 7 confocal optical sections). Recombination of tdTomato confirms the ependymal identity of the recorded cell. D, Cluster of dye-coupled cells at 5 DPI covering the dorsolateral $\left(\boldsymbol{D}_{1}\right)$, ventrolateral $\left(\boldsymbol{D}_{2}\right)$, and ventral $\left(\boldsymbol{D}_{3}\right)$ aspects of the CC (stacks of 47,21 , and 25 optical sections, respectively). $\boldsymbol{D}_{3}$, The cluster has a bundle of processes projecting to the ventral sulcus (arrowhead). $\boldsymbol{D}_{3}$, Inset, The expression of tdTomato in ependymal cells shows the cluster was within the ependymal cell layer. $\boldsymbol{E}$, Large cluster of dye-coupled cells spanning the lateral domain of the C( at $5 \mathrm{DPI}\left(\boldsymbol{E}_{1}\right.$, stack of 22 optical sections). Most of dye-coupled cells matched the expression of tdTomato. The cluster corresponded to a Type 1 cell phenotype ( $\left.\boldsymbol{E}_{2}\right)$. Cbx (100 $\left.\mu \mathrm{M}\right)$ increased the apparent $I R$ of the recorded cell, suggesting the gap junction coupling with neighboring cells $\left(\boldsymbol{E}_{3}\right)$. $\boldsymbol{F}$, The proportion of clusters of dye-coupled ependymal cells over single cells was significantly higher $(p<0.01)$ at $5 \mathrm{DPI}$ than in sham-injured animals. $G$, The volume of clusters of gap junction-coupled cells was similar in the CC of sham-injured and injured spinal cord $(p=0.48)$. ${ }^{*} p<0.05,{ }^{* *} p<0.01$, ns $=$ non significant.

cant difference in the density of $\mathrm{Cx} 26$ puncta within the epicenter $(0-2 \mathrm{~mm}$ around the epicenter) compared with rostral $(p<$ 0.001 , Kruskal-Wallis test) and caudal $(p<0.0001)$ regions $(2-4$ $\mathrm{mm}$ from the epicenter), which had a density similar to shaminjured animals (Fig. 5J; $p=0.99$ and $p=0.1$, respectively, Kruskal-Wallis test, with Dunn's post hoc). Similarly, the difference in EdU uptake between the epicenter and the rostral and caudal regions was significantly different (Fig. $5 K$; $p<0.0001$ and $p<0.001$, respectively, Kruskal-Wallis test, with Dunn's post hoc). This shows that the increase of $\mathrm{Cx} 26$ occurs locally around the injury site and is spatially correlated with the increased proliferation of ependymal cells.

In addition to forming gap junctions, unopposed connexin hemichannels play an important role in the nervous system, both in normal and pathological conditions (Bennett et al., 2003, 2012). Thus, we explored the presence of functional connexin hemichannels in ependymal cells of the adult intact spinal cord and the eventual plasticity during the acute phase of SCI. We found that incubation of adult spinal cord slices with EtBr resulted in robust EtBr uptake in many ependymal cells (Fig. 6 $A_{1}$ ), which was strongly reduced when slices were preincubated in 100 $\mu \mathrm{M}$ Cbx (Fig. $6 A_{2}, D_{1} ; p<0.0001$, Mann-Whitney $U$ test). Because $\mathrm{Cbx}$ is a nonselective connexin antagonist, we used the TAT-Gap19 peptide, which binds to the intracellular loop of Cx43 blocking hemichannel activity without altering Cx43 gap junctions (or other connexins) in the time span of our experiments (Abudara et al., 2014). In the presence of the inactive TATGap19 scrambled peptide (TAT-Gap19Scr), the uptake of EtBr was similar to that observed in control conditions (Fig. $6 B_{1} ; p=$ 0.40, Mann-Whitney $U$ test). However, uptake of EtBr in the presence of $100 \mu \mathrm{M}$ TAT-Gap19 was significantly reduced (Fig. $6 B_{2}, D_{1} ; p<0.0001$ Mann-Whitney $U$ test). Next, we asked 
whether hemichannel activity was also present in the reactive ependyma. Interestingly, at 5 DPI, we found no significant difference in EtBr uptake between the control and in medium containing Cbx (Fig. $6 C_{1}, D_{1} ; p=0.68$, Mann-Whitney $U$ test). Additionally, EtBr uptake at 5 DPI was significantly lower compared with the uninjured ependyma $(p<$ $0.0001)$ or TAT-Gap19Scr $(p<0.01)$ controls (Fig. $6 D_{2}$; Kruskal-Wallis test with Dunn's post hoc). This suggests that functional Cx43 hemichannels are downregulated during the early stages of the reaction of the ependyma to injury.

Our findings suggest that connexin signaling may be involved in the injuryinduced reactivation of the dormant CC stem cell niche. To test this idea, we blocked connexin signaling in vivo immediately after SCI. We locally applied Gap26 and Gap26Scr in Pluronic F127 hydrogel or Pluronic F127 with saline (vehicle) at the time of injury and injected EdU (two daily injections, from day 3 to day 5 after SCI; Fig. $7 A ; n=4$ animals per group). The proliferation response of ependymal cells to injury was strong when vehicle was applied and not significantly different from the proliferation rate observed when using Gap26Scr (Fig. $7 B_{1}, B_{2}, C ; p=0.9$, Kruskal-Wallis test with Dunn's post hoc). However, the blockade of connexins by Gap26 significantly reduced the proliferative reaction of ependymal cells to injury (Fig. $7 B_{3}, C$; $p<0.05$, Kruskal-Wallis test with Dunn's post hoc), suggesting that connexin signaling is involved in the "awakening" of ependymal cells. The average proliferation when using Pluronic F127containing vehicle or Gap26Scr was higher than that of the injured cord without the gel (Fig. 5I, K vs Fig. 7C). To test whether Pluronic F127 may affect proliferation, we applied the gel to the surface of sham-injured cords (Fig. 8A). We found that Pluronic F127 did not change significantly the number of $\mathrm{EdU}^{+}$nuclei in the ependyma or the dorsal surface of the cord (Fig. $8 B, C ; p=$ 0.27 and $p=0.50$, respectively, Nested $t$ test; $n=3$ animals per group). Furthermore, the gel seemed quite inert as did not generate a substantial inflammation judged by the number of $\mathrm{Iba1}^{+}$ cells (Fig. $8 D ; p=0.59$, Nested $t$ test; $n=3$ animals per group). It may be possible that Pluronic F127 gel within the injury site exerts some mechanical strain that could increase background proliferation as described in some stem cells (Vining and Mooney, 2017).

\section{Discussion}

Communication via gap junctions is a major regulator of the behavior of neural stem cells (Elias and Kriegstein, 2008). Here, we report that gap junction coupling within the CC of mice decreases from early postnatal life into adulthood, when the CC stem cell niche becomes quiescent (Sabourin et al., 2009; Alexovic Matiasová et al., 2017). In the early stages of the reaction to in-
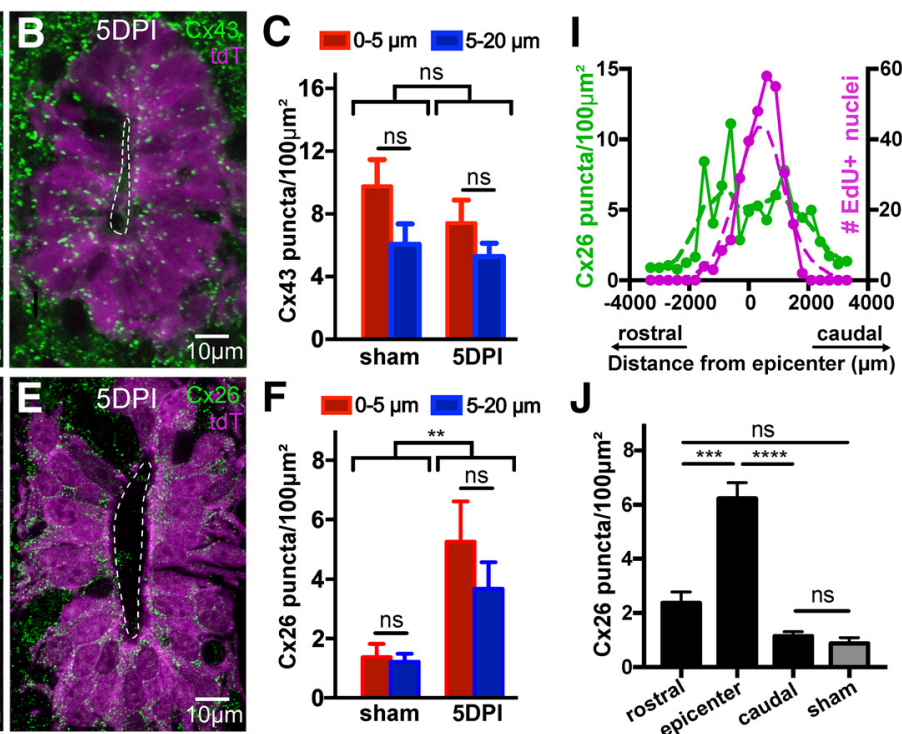

J
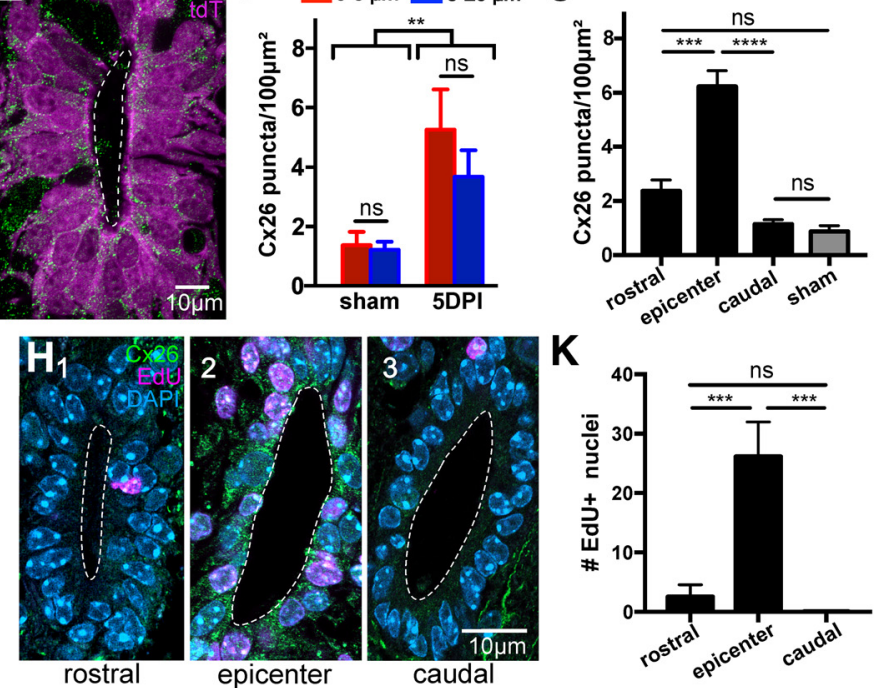

Figure 5. Injury-induced plasticity of connexin signaling in the CC. $A, B$, Expression profile of $(x 43$ in sham-injured and $5 \mathrm{DPI}$ ( (magenta) at 5 DPI. The lesion epicenter is located at 0 in the abscissa. J, Bar graph of the density of $(x 26$ puncta in a region around the lesion epicenter ( $0-2 \mathrm{~mm}$ around the epicenter) and in neighboring rostral and caudal regions (2-4 mm away from the epicenter). The density of (x26 puncta in the sham-injured spinal cord is also shown (gray bar). $\boldsymbol{K}$, Number of EdU ${ }^{+}$nuclei in the same regions as in the plot in J. All images are single confocal optical planes. $\mathbf{G}-\boldsymbol{K}$, Data obtained in $\mathbf{C 5 7 B L / 6 J}$ mice. ${ }^{* *} p<0.01$, ${ }^{* * *} p<0.001,{ }^{* * * *} p<0.0001$, ns $=$ non significant.

jury, gap junction coupling among adult ependymal cells increased, resembling their immature counterparts. Similar to stem cell niches in the embryo, $\mathrm{Cx} 43$ and $\mathrm{Cx} 26$ were expressed in the CC with a developmental downregulation of Cx26 that was reverted by injury. Our findings suggest that connexin signaling is involved in the early reaction of ependymal cells to injury, representing a potential target to modulate the contribution of the CC to self-repair.

Developmental plasticity of gap junction coupling in the CC Our data showed that the membrane properties of ependymal cells remained similar during postnatal development and after injury of the adult spinal cord. However, gap junction coupling between ependymal cells in the lateral domains of the CC was a common feature in neonatal mice but less frequent in adults. Proliferating radial glia in the developing cortex are dynamically coupled via gap junctions (LoTurco and Kriegstein, 1991) and pharmacological uncoupling prevents these progenitors entering the S-phase of the cell cycle (Bittman et al., 1997). Thus, the reduction of coupling between ependymal cells as the spinal cord matures is in line with the fact that proliferation in the CC peaks 

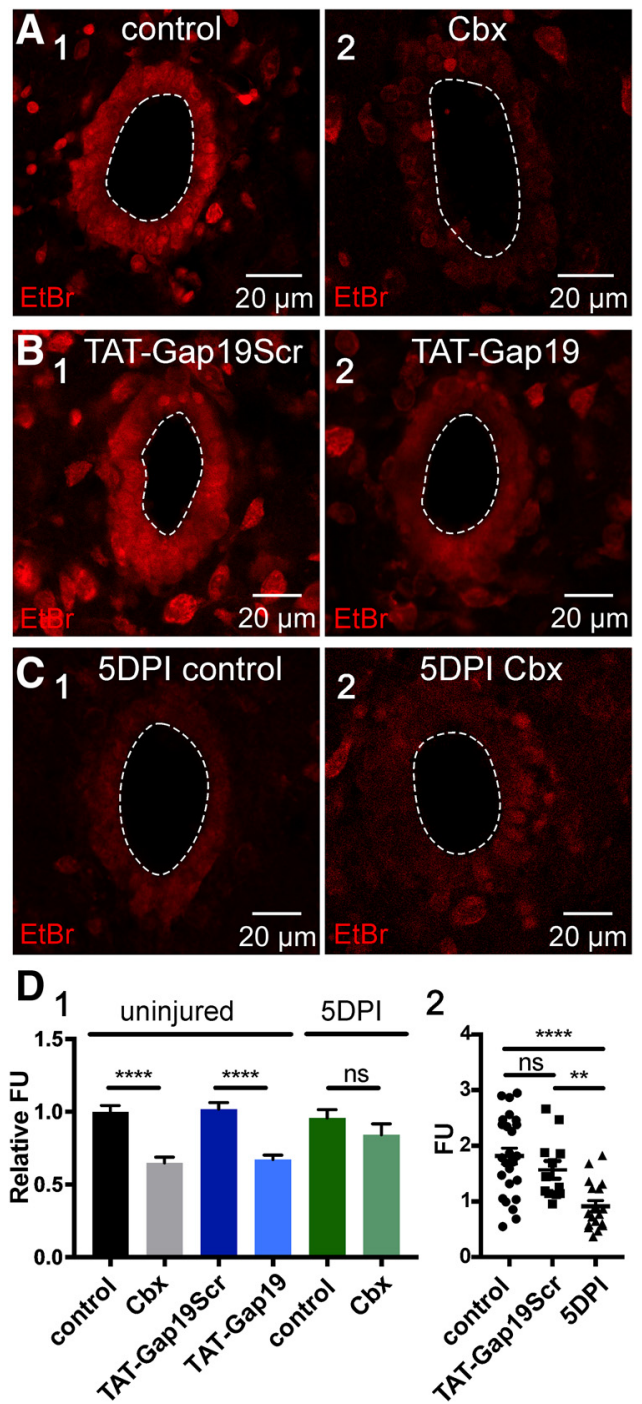

Figure 6. Connexin hemichannel activity is reduced at $5 \mathrm{DPI}$. $\boldsymbol{A}, \mathrm{EtBr}(4 \mu \mathrm{M})$ uptake in ependymal cells of the adult spinal cord (A1). Incubation of spinal cord slices with Cbx $(200 \mu \mathrm{M})$ significantly reduced $\mathrm{EtBr}$ uptake $(\boldsymbol{A} \mathbf{2}, p<0.0001)$. $\boldsymbol{B}$, The scrambled version of the $\mathrm{Cx} 43$ hemichannel specific blocker TAT-GAP19 did not affect EtBr uptake (B1, TAT-Gap19Scr), whereas the active peptide TAT-Gap19 $(100 \mu \mathrm{M})$ significantly reduced EtBr uptake $(\boldsymbol{B} 2, p<$ 0.0001).C, At 5 DPI, ependymal cells uptake less EtBr compared with the control. D1, Bar graphs represent the EtBr fluorescence units ( $\mathrm{FU}$ ) relative to the control conditions for each experiment $(A, C, E)$. D2, Dot plots of FU in control, in the presence of TAT-Gap19Scr (100 $\mu \mathrm{M})$ and at 5 DPI. There is a significant difference in connexin hemichannel activity between control and $5 \mathrm{DPI}$ ( $p<0.0001$ control vs $5 \mathrm{DPl} ; p<0.01$ between TAT-Gap19 and $5 \mathrm{DPI} ; p=0.99$ between TAT-Gap19 and control). All images represent single optical sections. All data were obtained in C57BL/6J mice. ${ }^{* *} p<0.01,{ }^{* * * *} p<0.0001$, ns $=$ non significant.

around P8 to decline to almost quiescence in adult rodents (Alexovic Matiasová et al., 2017).

Gap junction coupling in the CC of neonatal mice was correlated with the expression of $\mathrm{Cx} 26$ and $\mathrm{Cx} 43$, resembling the expression profile of connexins in neural progenitors of the developing brain (Dermietzel et al., 1989; Nadarajah et al., 1997). The fact that $\mathrm{Cx} 26$ puncta in the neonatal $\mathrm{CC}$ were evenly distributed compared with $\mathrm{Cx} 43$ suggests that connexin signaling in ependymal cells shares key features with bona fide stem cell niches of the developing mammalian brain (Nadarajah et al., 1997; Elias and Kriegstein, 2008). Progenitor-like cells in the CC of turtles (a vertebrate with self-repair capabilities) are coupled by $\mathrm{Cx} 43$ located close to the CC lumen, whereas $\mathrm{Cx} 26$ is expressed
A

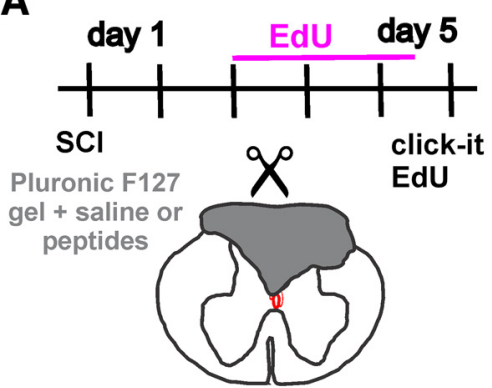

C

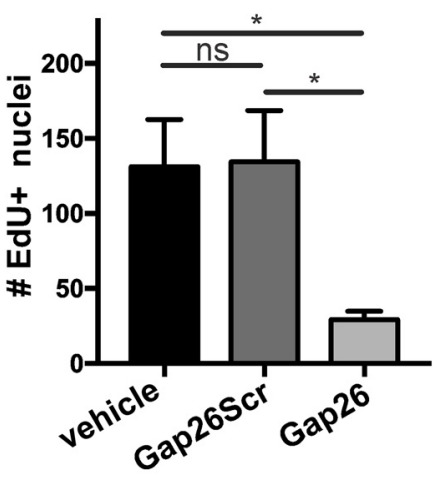

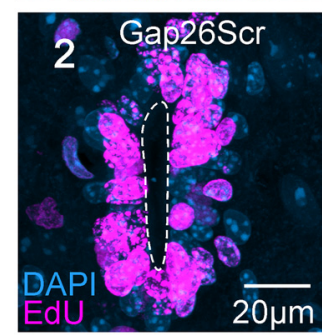

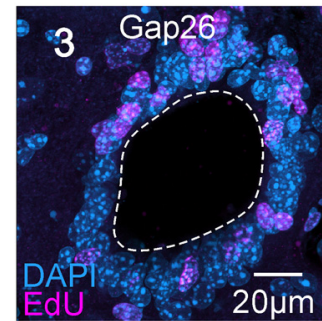

Figure 7. The proliferation of ependymal cells in response to $\mathrm{SCl}$ is reduced by connexin blockade. $A$, Experimental design to evaluate the role of connexin signaling in the reaction of ependymal cells to $\mathrm{SCl}$. $\boldsymbol{B}$, Numerous nuclei within the ependyma are labeled with EdU at 5 DP when vehicle $\left(\boldsymbol{B}_{1}\right)$ or the scrambled version of Gap26 ( $\boldsymbol{B}_{2}$, Gap26Scr $10 \mathrm{~mm}$ ) was applied. However, the number of $\mathrm{EdU}^{+}$nuclei was lower when Pluronic F127 hydrogel containing the connexin blocker Gap26 ( $\boldsymbol{B}_{3}, 10 \mathrm{~mm}$ ) filled the lesion site. $\boldsymbol{C}$, Bar graph represents that the number of $\mathrm{EdU}^{+}$nuclei at $5 \mathrm{DPI}$ was not significantly different between Pluronic F127containing saline (vehicle) or scrambled Gap26 (Gap26S, $10 \mathrm{~mm}$ ) but decreased significantly when the hydrogel contained $10 \mathrm{~mm}$ Gap26 ( $p<0.05$ ). The images represent stacks of 51 optical sections. All data were obtained in adult $\left(57 \mathrm{BL} / 6 \mathrm{~J}\right.$ mice. ${ }^{*} p<0.05$, ns $=$ non significant.

more distally (Russo et al., 2008), suggesting that the spatial profile of $\mathrm{Cx} 43$ and $\mathrm{Cx} 26$ expression is a phylogenetically conserved feature of active stem cell niches.

The low expression of Cx26 in the adult ependyma is in line with early studies showing that Cx26 in the brain disappears 3-6 weeks after birth (Dermietzel et al., 1989). The expression of $\mathrm{Cx} 26$ in $\mathrm{BrdU}^{+}$cells of the developing cortex is significantly higher than Cx43 (Bittman and LoTurco, 1999), suggesting that the low Cx26 in adult ependymal cells may be linked to a nonproliferative phenotype. In line with this, the spatial profile of Cx26 upregulation matched the increase in EdU uptake at 5 DPI.

Cx30 appears late in astrocytes during postnatal development and was also reported in ependymal cells of the brain (Kunzelmann et al., 1999). Although we found a similar temporal profile of Cx30 expression in the spinal cord parenchyma, ependymal cells lacked Cx30. This difference may be related to the fact ependymal cells in the spinal cord are different from those in the brain (Mirzadeh et al., 2008; Alfaro-Cervello et al., 2012).

Injury-induced plasticity of connexin signaling in the CC

Resumption of proliferation is an early event of the reaction of the CC to SCI (Mothe and Tator, 2005; Meletis et al., 2008; Sabelström et al., 2013). The increased incidence of coupling among ependymal cells at 5 DPI suggests that gap junction coupling is a component of the cellular mechanisms implied in the 
early reaction to injury and resembles a return to a state of connexin signaling similar to the active CC stem cell niche of neonatal mice (Sabourin et al., 2009), which has higher intrinsic regenerative potential (Li et al., 2016). Injury overruled the developmental downregulation of Cx26 in ependymal cells, whereas the expression of $\mathrm{Cx} 43$ did not change, in contrast with the upregulation of $\mathrm{Cx} 43$ reported in progenitors of the dentate gyrus after traumatic brain injury (Greer et al., 2017). Collectively, these results suggest that the injury-induced upregulation of Cx26 may be the molecular mechanism underlying the recoupling of ependymal cells in the reactive CC. However, we cannot rule out that recoupling is mediated by a change in $\mathrm{Cx} 43$ gating or assembly into gap junctions (Pogoda et al., 2016). Indeed, Cx43 has been proposed to underlie coupling of progenitor-like cells in the CC of turtles because its spatial profile of expression matches the location of clusters of dyecoupled cells (Russo et al., 2008).

Our EtBr uptake experiments indicate that, in the intact CC of adult mice, there is a population of functional $\mathrm{Cx} 43$ hemichannels that decrease after injury. A parsimonious interpretation of our data is that unopposed hemichannels may be recruited for gap junction assembly in ependymal cells reactive to injury. Alternatively, a negative interaction with upregulated Cx26 after injury may reduce the population of permeable Cx43 hemichannels (Gemel et al., 2004). In glial cells, Cx43 seems neuroprotective when assembled into gap junctions (Kozoriz and Naus, 2013) or neurotoxic in the form of hemichannels (Orellana et al., 2009). We speculate that the reduction of hemichannel activity may enhance the viability of CC progenitor-like cells within injured tissue.

\section{Connexins and SCI}

The role played by connexins in the response of the nervous system to injury is controversial, with reports suggesting that increased expression of $\mathrm{Cx} 43$ is detrimental (Frantseva et al., 2002a,b), whereas others show that Cx43 downregulation results in an expansion of the lesion size (Siushansian et al., 2001; Nakase et al., 2004). In the rat spinal cord, Cx43 mRNA increases as early as $4 \mathrm{~h}$ after complete transection and remains elevated at least 4 weeks after injury (Lee et al., 2005). The interference with $\mathrm{Cx} 43$ function after SCI reduces the reactive astrogliosis and neuronal death (O'Carroll et al., 2008) and improves functional recovery (Cronin et al., 2008).

The fact that the size of clusters of gap junction-coupled cells was similar in neonatal, intact, and injured adult CC suggests that ependymal cells form small-world networks to regulate proliferation as in embryonic progenitors (Malmersjö et al., 2013). In line with this idea, our in vivo experiments show that connexin blockade around the lesion largely prevented the injury-induced significant.

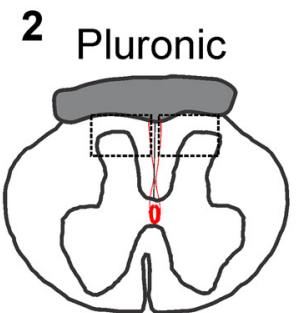

3
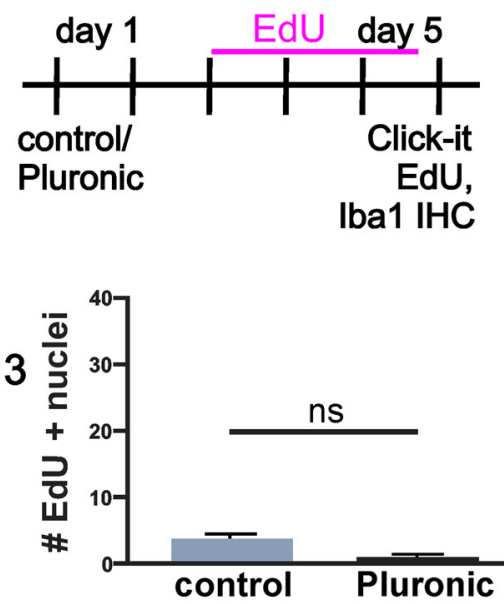

Pluronic
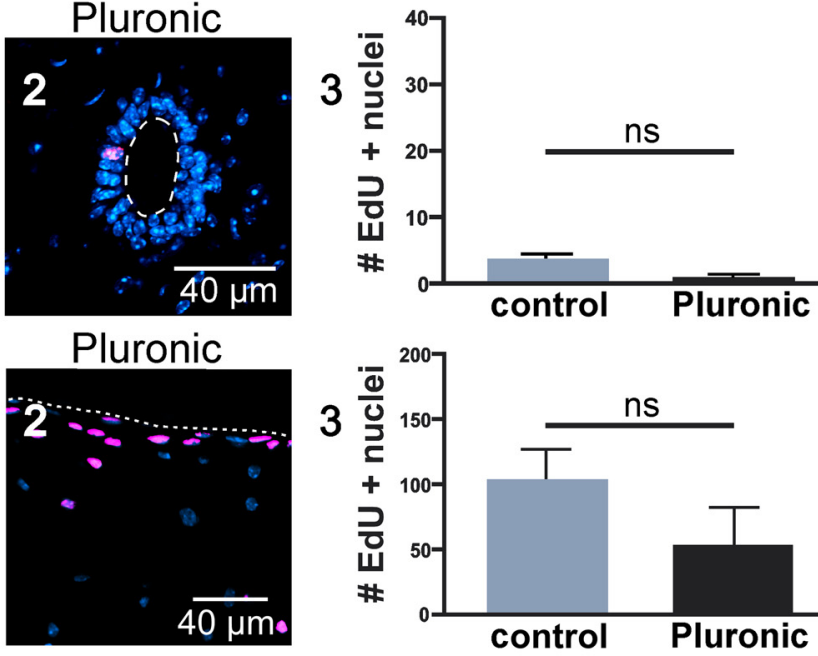

Pluronic
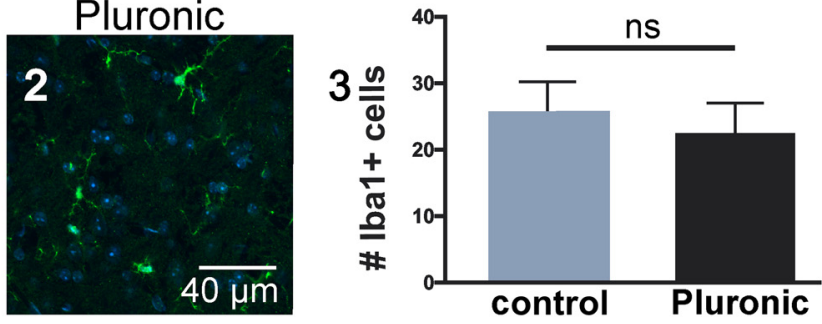

Figure 8. Pluronic F127 gel applied on the dorsal aspect of the spinal cord does not affect proliferation. $\boldsymbol{A}$, Experimental design to test whether Pluronic F127 affects proliferation. Sham-injured animals served as controls $\left(\boldsymbol{A}_{\boldsymbol{1}}\right)$; whereas in the test group, and Pluronic F127 ( $\left.\boldsymbol{B}_{2}\right)$ mice. No significant differences were found between the two groups $\left(\boldsymbol{B}_{3} ; p=0.27\right)$. $\boldsymbol{C}$, EdU uptake in

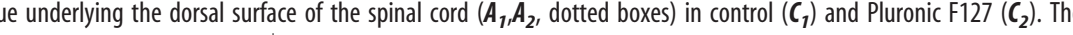
immunohistochemistry in the dorsal surface of the $\operatorname{cord}\left(\boldsymbol{A}_{1}, \boldsymbol{A}_{2}\right.$, boxed areas) in control $\left(\boldsymbol{D}_{1}\right)$ and Pluronic F127 mice $\left(\boldsymbol{D}_{2}\right)$. The number of $\mathrm{Iba}^{+}$cells in both groups showed no significant differences $\left(\boldsymbol{D}_{3} ; p=0.59\right)$. All data were obtained in adult $(57 \mathrm{BL} / 6 \mathrm{~J}$ mice. ns $=$ non

resumption of ependymal cell proliferation. The molecular mechanisms by which connexins may regulate the behavior of progenitor cells are not clear. Strong metabolic coupling of spinal precursors at their apical poles, a critical cell compartment in neural progenitors (Taverna et al., 2014), may allow an efficient communication of molecules that regulate cell division or differentiation (Bruzzone and Dermietzel, 2006). Gap junctions may provide genetic communication among neighboring progenitors as they allow the passage of microRNA, with $\mathrm{Cx} 43$ being more efficient than Cx26 (Zong et al., 2016). Cx43 and Cx26 may also affect the proliferation, migration, and differentiation of spinal precursors by nonconventional mechanisms via molecular interactions with a variety of proteins (Kardami et al., 2007). Interestingly, the role of connexins in neuronal migration during development in the cortical plate is mediated by the facilitation of cell-cell adhesion and not by their functions as channels (Elias et 
al., 2007). Although Cx43 and Cx26 are both expressed in the CC, developmental and injury-induced plasticity seemed related mostly to Cx26, a connexin associated to mitotically active progenitor cells (Bittman and LoTurco, 1999). Interestingly, the duo $\mathrm{Cx} 43 / \mathrm{Cx} 26$ is expressed in the skin and has a major role in wound healing (Wong et al., 2016). Cx26 is expressed in proliferating keratinocytes and downregulated as differentiation proceeds to be weakly detected in the normal epidermis (Kretz et al., 2004). Persistent expression of Cx26 maintains the epidermis in a hyperproliferative state (Djalilian et al., 2006), suggesting that Cx26 is a key regulator of proliferation in epithelia. Remarkably, Cx26 is upregulated in keratinocytes within the edge of a wound (Pedersen et al., 2003). The fact that Cx 26 in the adult CC is upregulated around the lesion epicenter resembles the events in the wounded skin and suggests that Cx26 may be part of a general mechanism to regulate cell proliferation during healing. In addition, Cx26 increases cell migration in a scrape wound model by lowering cell adhesion (Polusani et al., 2016) and interacts with actin to drive migration in the developing cortex (Elias et al., 2007), raising the possibility that $C \times 26$ may be also involved in the migration of the ependyma-derived cells toward the scar. Cx43 could also affect ependymal cell proliferation as $\mathrm{Cx} 43$ is necessary for the mitogenic effect of FGF in neural progenitors (Cheng et al., 2004). Future studies should address the specific functional role of $\mathrm{Cx} 26$ and $\mathrm{Cx} 43$ in the biology of ependymal cells by selective genetic deletion using loxP transgenic mice. A better understanding of the role played by gap junction coupling and connexin hemichannels in the normal and injury-activated CC will provide valuable clues to improve the contribution of this stem cell niche to self-repair.

\section{References}

Abudara V, Bechberger J, Freitas-Andrade M, De Bock M, Wang N, Bultynck G, Naus CC, Leybaert L, Giaume C (2014) The connexin43 mimetic peptide Gap19 inhibits hemichannels without altering gap junctional communication in astrocytes. Front Cell Neurosci 8:306.

Alexovic Matiasová A, Sevc J, Tomori Z, Gombalová Z, Gedrová S, Daxnerová Z (2017) Quantitative analyses of cellularity and proliferative activity reveals the dynamics of the central canal lining during postnatal development of the rat. J Comp Neurol 525:693-707.

Alfaro-Cervello C, Soriano-Navarro M, Mirzadeh Z, Alvarez-Buylla A, Garcia-Verdugo JM (2012) Biciliated ependymal cell proliferation contributes to spinal cord growth. J Comp Neurol 520:3528-3552.

Barry PH (1994) JPCalc, a software package for calculating liquid junction potential corrections in patch-clamp, intracellular, epithelial and bilayer measurements and for correcting junction potential measurements. J Neurosci Methods 51:107-116.

Bennett MV, Contreras JE, Bukauskas FF, Sáez JC (2003) New roles for astrocytes: gap junction hemichannels have something to communicate. Trends Neurosci 26:610-617.

Bennett MV, Garré JM, Orellana JA, Bukauskas FF, Nedergaard M, Sáez JC (2012) Connexin and pannexin hemichannels in inflammatory responses of glia and neurons. Brain Res 1487:3-15.

Bittman KS, LoTurco JJ (1999) Differential regulation of connexin 26 and 43 in murine neocortical precursors. Cereb Cortex 9:188-195.

Bittman K, Owens DF, Kriegstein AR, LoTurco JJ (1997) Cell coupling and uncoupling in the ventricular zone of developing neocortex. J Neurosci 17:7037-7044.

Bruzzone R, Dermietzel R (2006) Structure and function of gap junctions in the developing brain. Cell Tissue Res 326:239-248.

Cai T, Seymour ML, Zhang H, Pereira FA, Groves AK (2013) Conditional deletion of Atoh1 reveals distinct critical periods for survival and function of hair cells in the organ of Corti. J Neurosci 33:10110-10122.

Cheng A, Tang H, Cai J, Zhu M, Zhang X, Rao M, Mattson MP (2004) Gap junctional communication is required to maintain mouse cortical neural progenitor cells in a proliferative state. Dev Biol 272:203-216.

Chever O, Lee CY, Rouach N (2014) Astroglial Connexin43 Hemichannels
Tune Basal Excitatory Synaptic Transmission. J Neurosci 34:1122811232.

Cizkova D, Nagyova M, Slovinska L, Novotna I, Radonak J, Cizek M, Mechirova E, Tomori Z, Hlucilova J, Motlik J, Sulla I Jr, Vanicky I (2009) Response of ependymal progenitors to spinal cord injury or enhanced physical activity in adult rat. Cell Mol Neurobiol 29:999-1013.

Chittajallu R, Chen Y, Wang H, Yuan X, Ghiani CA, Heckman T, McBain CJ, Gallo V (2002) Regulation of Kv1 subunit expression in oligodendrocyte progenitor cells and their role in G1/S phase progression of the cell cycle. Proc Natl Acad Sci USA 99:2350-2355.

Connors BW (2012) Tales of a dirty drug: carbenoxolone, gap junctions, and seizures. Epilepsy Curr 12:66-68.

Cronin M, Anderson PN, Cook JE, Green CR, Becker DL (2008) Blocking connexin 43 expression reduces inflammation and improves functional recovery after spinal cord injury. Mol Cell Neurosci 39:152-160.

Dermietzel R, Traub O, Hwang TK, Beyer E, Bennett MV, Spray DC, Willecke K (1989) Differential expression of three gap junction proteins in developing and mature brain tissues. Proc Natl Acad Sci U S A 86:10148-10152.

Djalilian AR, McGaughey D, Patel S, Seo EY, Yang C, Cheng J, Tomic M, Sinha S, Ishida-Yamamoto A, Segre JA (2006) Connexin 26 regulates epidermal barrier and wound remodeling and promotes psoriasiform response. J Clin Invest 116:1243-1253.

Elias LA, Kriegstein AR (2008) Gap junctions: multifaceted regulators of embryonic cortical development. Trends Neurosci 31:243-250.

Elias LA, Wang DD, Kriegstein AR (2007) Gap junction adhesion is necessary for radial migration in the neocortex. Nature 448:901-907.

Evans WH, Bultynck G, Leybaert L (2012) Manipulating connexin communication channels: use of peptidomimetics and the translational outputs. J Membr Biol 245:437-449.

Frantseva MV, Kokarovtseva L, Naus CG, Carlen PL, MacFabe D, Perez Velazquez JL (2002a) Specific gap junctions enhance the neuronal vulnerability to brain traumatic injury. J Neurosci 22:644-653.

Frantseva MV, Kokarovtseva L, Perez Velazquez JL (2002b) Ischemiainduced brain damage depends on specific gap-junctional coupling. J Cereb Blood Flow Metab 22:453-462.

Frisén J, Fried K, Sjögren AM, Risling M (1993) Growth of ascending spinal axons in CNS scar tissue. Int J Dev Neurosci 4:461-475.

Gemel J, Valiunas V, Brink PR, Beyer EC (2004) Connexin43 and connexin26 form gap junctions, but not heteromeric channels in co-expressing cells. JCell Sci 117:2469-2480.

Göritz C, Frisén J (2012) Neural stem cells and neurogenesis in the adult. Cell Stem Cell 10:657-659.

Greer K, Chen J, Brickler T, Gourdie R, Theus MH (2017) Modulation of gap junction-associated $\mathrm{Cx} 43$ in neural stem/progenitor cells following traumatic brain injury. Brain Res Bull 134:38-46.

Juszczak GR, Swiergiel AH (2009) Properties of gap junction blockers and their behavioural, cognitive and electrophysiological effects: animal and human studies. Prog Neuropsychopharmacol Biol Psychiatry 33:181198.

Kardami E, Dang X, Iacobas DA, Nickel BE, Jeyaraman M, Srisakuldee W, Makazan J, Tanguy S, Spray DC (2007) The role of connexins in controlling cell growth and gene expression. Prog Biophys Mol Biol 94:245-264.

Kozoriz MG, Naus CC (2013) Gap junction-mediated neuroprotection. In: Gap junctions in the brain: physiological and pathological roles (Dere E, ed), pp 231-246. Amsterdam: Elsevier.

Kretz M, Maass K, Willecke K (2004) Expression and function of connexins in the epidermis, analyzed with transgenic mouse mutants. Eur J Cell Biol 83:647-654.

Kunze A, Congreso MR, Hartmann C, Wallraff-Beck A, Hüttmann K, Bedner P, Requardt R, Seifert G, Redecker C, Willecke K, Hofmann A, Pfeifer A, Theis M, Steinhäuser C (2009) Connexin expression by radial glia-like cells is required for neurogenesis in the adult dentate gyrus. Proc Natl Acad Sci U S A 106:11336-11341.

Kunzelmann P, Schröder W, Traub O, Steinhäuser C, Dermietzel R, Willecke K (1999) Late onset and increasing expression of the gap junction protein connexin 30 in adult murine brain and long-term cultured astrocytes. Glia 25:111-119.

Lee IH, Lindqvist E, Kiehn O, Widenfalk J, Olson L (2005) Glial and neuronal connexin expression patterns in the rat spinal cord during development and following injury. J Comp Neurol 489:1-10.

Li X, Floriddia EM, Toskas K, Fernandes KJ, Guérout N, Barnabé-Heider F 
(2016) Regenerative potential of ependymal cells for spinal cord injuries over time. EBioMedicine 13:55-65.

LoTurco JJ, Kriegstein AR (1991) Clusters of coupled neuroblasts in embryonic neocortex. Science 252:563-565.

Malmersjö S, Rebellato P, Smedler E, Planert H, Kanatani S, Liste I, Nanou E, Sunner H, Abdelhady S, Zhang S, Andäng M, El Manira A, Silberberg G, Arenas E, Uhlén P (2013) Neural progenitors organize in small-world networks to promote cell proliferation. Proc Natl Acad Sci U S A 110:E1524-E1532.

Marichal N, García G, Radmilovich M, Trujillo-Cenóz O, Russo RE (2012) Spatial domains of progenitor-like cells and functional complexity of a stem cell niche in the neonatal rat spinal cord. Stem Cells 30:2020-2031.

Meletis K, Barnabé-Heider F, Carlén M, Evergren E, Tomilin N, Shupliakov O, Frisén J (2008) Spinal cord injury reveals multilineage differentiation of ependymal cells. PLoS Biol 6:1494-1507.

Mirzadeh Z, Merkle FT, Soriano-Navarro M, Garcia-Verdugo JM, AlvarezBuylla A (2008) Neural stem cells confer unique pinwheel architecture to the ventricular surface in neurogenic regions of the adult brain. Cell Stem Cell 3:265-278.

Mothe AJ, Tator CH (2005) Proliferation, migration, and differentiation of endogenous ependymal region stem/progenitor cells following minimal spinal cord injury in the adult rat. Neuroscience 131:177-187.

Nadarajah B, Jones AM, Evans WH, Parnavelas JG (1997) Differential expression of connexins during neocortical development and neuronal circuit formation. J Neurosci 17:3096-3111.

Nakase T, Söhl G, Theis M, Willecke K, Naus CC (2004) Increased apoptosis and inflammation after focal brain ischemia in mice lacking connexin 43 in astrocytes. Am J Pathol 164:2067-2075.

O'Carroll SJ, Alkadhi M, Nicholson LF, Green CR (2008) Connexin 43 mimetic peptides reduce swelling, astrogliosis, and neuronal cell death after spinal cord injury. Cell Commun Adhes 15:27-42.

Orellana JA, Sáez PJ, Shoji KF, Schalper KA, Palacios-Prado N, Velarde V, Giaume C, Bennett MV, Sáez JC (2009) Modulation of brain hemichannels and gap junction channels by pro-inflammatory agents and their possible role in neurodegeneration. Antioxid Redox Signal 11:369-399.

Pardo LA (2004) Voltage-gated potassium channels in cell proliferation. Physiology 19:285-292.

Peça J, Feliciano C, Ting JT, Wang W, Wells MF, Venkatraman TN, Lascola CD, Fu Z, Feng G (2011) Shank3 mutant mice display autistic-like behaviours and striatal dysfunction. Nature 472:437-442.

Pedersen TX, Leethanakul C, Patel V, Mitola D, Lund LR, Danø K, Johnsen M, Gutkind JS, Bugge TH (2003) Laser capture microdissection-based in vivo genomic profiling of wound keratinocytes identifies similarities and differences to squamous cell carcinoma. Oncogene 22:3964-3976.
Pogoda K, Kameritsch P, Retamal MA, Vega JL (2016) Regulation of gap junction channels and hemichannels by phosphorylation and redox changes: a revision. BMC Cell Biol 17 [Suppl 1]:11.

Polusani SR, Kalmykov EA, Chandrasekhar A, Zucker SN, Nicholson BJ (2016) Cell coupling mediated by connexin 26 selectively contributes to reduced adhesivity and increased migration. J Cell Sci 129:4399-4410.

Rash JE, Yasumura T, Davidson KG, Furman CS, Dudek FE, Nagy JI (2001) Identification of cells expressing $\mathrm{Cx} 43, \mathrm{Cx} 30, \mathrm{Cx} 26, \mathrm{C} \times 32$ and $\mathrm{Cx} 36$ in gap junctions of rat brain and spinal cord. Cell Commun Adhes 8:315-320.

Rodríguez-Jimenez FJ, Alastrue A, Stojkovic M, Erceg S, Moreno-Manzano V (2016) Connexin 50 modulates Sox 2 expression in spinal-cord-derived ependymal stem/progenitor cells. Cell Tissue Res 365:295-307.

Russo RE, Reali C, Radmilovich M, Fernández A, Trujillo-Cenóz O (2008) Connexin 43 delimits functional domains of neurogenic precursors in the spinal cord. J Neurosci 28:3298-3309.

Sabelström H, Stenudd M, Réu P, Dias DO, Elfineh M, Zdunek S, Damberg P, Göritz C, Frisén J (2013) Resident neural stem cells restrict tissue damage and neuronal loss after spinal cord injury in mice. Science 342:637-640.

Sabelström H, Stenudd M, Frisén J (2014) Neural stem cells in the adult spinal cord. Exp Neurol 260:44-49.

Sabourin JC, Ackema KB, Ohayon D, Guichet PO, Perrin FE, Garces A, Ripoll C, Charité J, Simonneau L, Kettenmann H, Zine A, Privat A, Valmier J, Pattyn A, Hugnot JP (2009) A mesenchymal-like ZEB1(+) niche harbors dorsal radial glial fibrillary acidic protein-positive stem cells in the spinal cord. Stem Cells 27:2722-2733.

Schaarschmidt G, Wegner F, Schwarz SC, Schmidt H, Schwarz J (2009) Characterization of voltage-gated potassium channels in human neural progenitor cells. PLoS One 4:e6168.

Schneider CA, Rasband WS, Eliceiri KW (2012) NIH image to ImageJ: 25 years of image analysis. Nat Methods 9:671-675.

Siushansian R, Bechberger JF, Cechetto DF, Hachinski VC, Naus CC (2001) Connexin 43 null mutation increases infarct size after stroke. J Comp Neurol 440:387-394.

Taverna E, Götz M, Huttner WB (2014) The cell biology of neurogenesis: toward an understanding of the development and evolution of the neocortex. Annu Rev Cell Dev Biol 30:465-502.

Vining KH, Mooney DJ (2017) Mechanical forces direct stem cell behaviour in development and regeneration. Nat Rev Mol Cell Biol 18:728-742.

Wong P, Tan T, Chan C, Laxton V, Chan YW, Liu T, Wong WT, Tse G (2016) The role of connexins in wound healing and repair: novel therapeutic approaches. Front Physiol 7:596.

Zong L, Zhu Y, Liang R, Zhao HB (2016) Gap junction mediated miRNA intercellular transfer and gene regulation: a novel mechanism for intercellular genetic communication. Sci Rep 6:19884. 